\title{
The effects of road pricing on driver behavior and air pollution
}

\author{
Matthew Gibson ${ }^{\mathrm{a}, *}$, Maria Carnovale ${ }^{\mathrm{b}}$ \\ ${ }^{a}$ Department of Economics, Williams College, Schapiro Hall, 24 Hopkins Hall Dr., Williamstown MA \\ 01267 \\ ${ }^{b}$ CERTeT, Università Bocconi and Duke University, Duke Box 90239, Durham, NC 27708
}

\begin{abstract}
Exploiting the natural experiment created by an unanticipated court injunction, we evaluate driver responses to road pricing. We find evidence of intertemporal substitution toward unpriced times and spatial substitution toward unpriced roads. The effect on traffic volume varies with public transit availability. Net of these responses, Milan's pricing policy reduces air pollution substantially, generating large welfare gains. In addition, we use long-run policy changes to estimate price elasticities.
\end{abstract}

Keywords: road pricing, traffic policy, air pollution

\section{Introduction}

Growing air pollution, congestion, and accident externalities from vehicle traffic have produced increasing interest in policy remedies. Beijing and Mexico City bar vehicles from their roads on some days based on their license plate numbers (Davis, 2008; Viard and Fu, 2014; Wang et al., 2014). Many German cities have created Low Emissions Zones (Wolff, 2014), which prohibit dirtier vehicles within their borders. Stockholm, London, and Milan charge fees to enter congested downtown areas. In the US, the Department of Transportation is currently sponsoring a large number of road pricing experiments, including San Francisco's Golden Gate Bridge, Interstate 95 near Miami, SR520 near Seattle, and Interstate 35W near Minneapolis (DeCorla-Souza, 2004; Xie, 2013). Economists have raised concerns over nonprice policies because behavioral responses can be so large that net policy benefits may be zero, or even negative (Davis, 2008; Gallego et al., 2013). Theory suggests that road pricing might be more efficient (Vickrey, 1963; Arnott et al., 1993), but this prediction depends on driver responses. On which margins do drivers respond to road pricing, and how large are such responses?

\footnotetext{
${ }^{*}$ Corresponding author

Email addresses: mg17@williams.edu (Matthew Gibson), maria.carnovale@duke.edu (Maria Carnovale)
} 
Confounding factors typically make traffic policies difficult to evaluate. Drivers know the policy start date well in advance and may begin to adjust their behavior beforehand, which attenuates estimated effects. Municipalities typically increase public transit service at the same time they implement road pricing or a driving restriction. This makes it impossible to estimate the effect of the policy in isolation. For example, Eliasson et al. (2009) point out that Stockholm expanded bus service at the same time it implemented a congestion charge. Because the buses used for the expansion were older and dirtier, the reduction in emissions within the charge area was muted. Milan first implemented a congestion charge concurrent with, "traffic calming measures, new bus lanes, increased bus frequency, increases in parking restrictions and fees, and medium-term policies such as park-and-ride facilities and underground network extensions" (Rotaris et al., 2010).

To address these identification challenges, we exploit a natural experiment: in late July 2012, an Italian court unexpectedly suspended Milan's road pricing policy, called "Area C." The city reinstated pricing eight weeks later. Using unique traffic data at 15-minute resolution, our study examines behavioral responses to Milan's policy, which requires drivers entering the city center to pay $€ 5$ on weekdays 7:30AM-7:30PM. Drivers respond to pricing in two ways: 1) shifting trips to the unpriced period, just before 7:30AM or after 7:30PM; and 2) driving around the boundary of the priced area.

Net of these behavioral responses, we find the Area $\mathrm{C}$ policy reduces vehicle entries into the priced area by 14.5 percent and air pollution by 6 to 17 percent. The latter effect is large, particularly given that the priced region is just five percent of Milan's land area and the city has an unusually clean vehicle fleet. Using a well-identified US estimate of willingness to pay from Bayer et al. (2009) and scaling for income in Milan, we calculate that this pollution reduction increases welfare by approximately $\$ 3$ billion annually. Routes without public transit experience large traffic changes from pricing, while those with public transit experience much smaller changes. We provide evidence that this surprising result may arise from residential sorting: residents who live near public transit may strongly prefer public transit. In addition, we use changes in Milan's pricing policy across the 2008-2011 and 2012 periods to estimate elasticities: city-center entries by charged vehicles decrease .3 percent in response to a one percent price increase.

This study contributes to the empirical literature on second-best road pricing policies (Small et al., 2005; Small and Verhoef, 2007; Xie, 2013). Closely related to our analysis are Olszewski and Xie (2005), which analyzes the cordon charge and expressway pricing in Singapore, Santos and Fraser (2006) and Santos (2008) on the London cordon charge, and Eliasson et al. (2009) on the Stockholm cordon charge. These studies find cordon charges do reduce traffic within the priced area. Also related are Foreman (2013) and Small and 
Gomez-Ibanez (1998), which find evidence of intertemporal substitution in response to timevarying tolls. Our work complements the theoretical literature on second-best road pricing (Lévy-Lambert, 1968; Marchand, 1968; Verhoef et al., 1996), particularly the literature on cordon charges (Mun et al., 2003; Verhoef, 2005). Finally, we contribute to the literature on environmental effects of traffic policies. Many such studies have found no evidence of air quality improvements (Transport for London, 2005, 2008; Invernizzi et al., 2011). Authors commonly attribute this to driver substitution behaviors or exploitation of policy loopholes (Davis, 2008; Gallego et al., 2013). In important work, Wolff (2014) finds that German Low Emissions Zones reduce the concentration of particles with a diameter of 10 microns or less (PM10) by approximately 9 percent; this study is particularly significant given efforts by European cities to meet stringent air quality standards.

Our study is unique in obtaining unconfounded causal estimates of behavioral responses to road pricing and net road pricing effectiveness. This is the first analysis to examine removal, rather than imposition, of a traffic policy. Other studies have used indirect measures of traffic (such as gasoline sales or vehicle registrations) or hourly vehicle counts, but to the best of our knowledge ours is the first to combine direct, high-resolution measures of traffic volume with air pollution data. Finally, our finding that the net effect of pricing varies with public transit availability is novel. It contributes to the literature on public transit and air quality (Friedman et al., 2001) and adds a new dimension to the literature on traffic policies.

The remainder of the paper proceeds as follows. Section 2 provides policy background and describes the natural experiment. Section 3 covers data, Section 4 describes our estimating equations, and Section 5 discusses results. Section 6 concludes.

\section{Background}

Located in the center of Milan, Area C includes approximately 8.2 square kilometers (5 percent of city land area) and 77,000 residents (6 percent of population). The boundary follows the Cerchia dei Bastioni, the route of the walls built under Spanish control in 1549. Many of the portals still stand today, though the walls are largely gone. Figure A2 illustrates the area.

Milan provides high levels of public transit, including four subway lines, 19 tram lines, 120 bus lines, and 4 trolley lines. Together these lines transport 700 million passengers across 155 million kilometers per year. The 80-kilometer subway network is larger than all other Italian subways combined (Azienda Transporti Milanesi, 2013). Public transit has a 41 percent mode share in the city, followed by cars at 30 percent, walking at 17 percent, bicycles at 6 percent, and motorbikes at 6 percent (Martino, 2012). The average round-trip 
commute in Milan takes 53 minutes, comparable to US cities like Dallas (52 minutes), Seattle (55 minutes), and Los Angeles (56 minutes; Toronto Board of Trade, 2011).

Milan is one of the most polluted large cities in Europe. From 2002 through 2010 the city exceeded the EU standard for PM10 on an average of 133 days per year (Danielis et al., 2011). Since the mid 1990s the city has experimented with traffic policies intended to curb its air pollution problem. Milan's first major road pricing program, called Ecopass, ran from January 1, 2008 to December 31, 2011. Drivers paid a fee to enter Area C that varied with the emissions from their vehicles. Vehicles meeting the Euro 3 standard paid nothing, while the dirtiest diesel vehicles paid $€ 10 .{ }^{1}$ The charge applied weekdays 7:30AM-7:30PM. Drivers could pay by internet, phone, or at the bank. The city enforced the charge using license plate-reading cameras located at the 43 entrances to Area C (Danielis et al., 2011). Drivers who entered without paying faced fines of $€ 70-€ 275$ (la Repubblica, 2008). Approximately 2 percent of entering vehicles each day incurred fines (Martino, 2012).

In June 2011 the voters of Milan overwhelmingly approved continued road pricing, with 79 percent in favor (Danielis et al., 2011). ${ }^{2}$ As of January 16, 2012, the city implemented a $€ 5$ congestion charge for most vehicles entering Area $C$ weekdays 7:30AM-7:30PM. This policy was named Area C. ${ }^{3}$ Motorcycles and public vehicles (e.g. ambulances) were exempted. ${ }^{4}$ Administrative details were largely the same as those for Ecopass. Drivers gained the option to pay by direct debit, using a radio reflector placed in the vehicle (similar to FasTrak or E-ZPass in the US). Violators were fined $€ 87$ (Carra, 2012).

On July 25, 2012, a court unexpectedly suspended the Area C congestion charge in response to a lawsuit by Mediolanum Parking (Povoledo, 2012). More than ten previous lawsuits against Ecopass and Area $\mathrm{C}$ had failed, so the suspension provoked surprise from the press (Carra and Gallione, 2012). Charge enforcement halted the next day, July 26. There was no press coverage prior to the court injunction, suggesting the decision was completely unanticipated. The duration of the suspension was unknown and some observers believed it would be permanent (Carra, 2012). Political forces marshaled on both sides. The mayor declared, "We will save Area C." Meanwhile the opposition called suspension the "death" of Area C, "the defeat of ideological fervor and the victory of Milan's productivity and

\footnotetext{
${ }^{1}$ Vehicles built prior to imposition of EU emissions standards were prohibited from October 15 through April 15. Drivers received a 50\% discount on the first 50 entries and a $40 \%$ discount on the next 50 entries. Residents of Area $\mathrm{C}$ were also eligible for discounts (Rotaris et al., 2010).

${ }^{2} 49$ percent of voters participated. The referendum did not specify the exact form the continued program would take.

${ }^{3}$ Vehicles classified diesel Euro 3 or below, or gasoline Euro 0 or below, were prohibited. Private vehicles over $7 \mathrm{~m}$ long were also prohibited. Scooters, motorcycles, and alternative-fuel vehicles, including hybrids, were exempted. Residents paid $€ 2$ per entry (City of Milan, 2012; Milan Tourism, 2012).

${ }^{4}$ This category includes mopeds and powered scooters.
} 
good sense" (Carra, 2012). The city altered neither public transit service nor parking fees in response to the injunction. On September 6, the city announced the charge would be reinstated as of September 17, 2012. ${ }^{5}$ For a timeline of these events, see Figure 1.

\section{Data}

Our traffic data come from AMAT and the Settore Pianificazione e Programmazione Mobilità e Trasporto Pubblico Comune di Milano. For Area C, we have entries by vehicle type and entry portal at 15-minute resolution, 2008-2012. There are 43 entry portals. These data are recorded by the license plate cameras used to enforce the Area $\mathrm{C}$ charge. In addition, we have counts of passing vehicles at 15-minute resolution, 2008-2012. These data are measured by 748 buried sensors, mostly outside Area C. ${ }^{6}$ Table 1 reports descriptive statistics for both data sets at the daily level (aggregating over sensors/cameras and 15-minute intervals).

Our pollution and weather data come from ARPA Lombardia, the provincial air quality agency. We have pollution and weather data at the monitor level, from 2003 through February 2013. Measured pollutants include carbon monoxide (CO), particles 10 microns or less in diameter (PM10), and particles 2.5 microns or less in diameter (PM2.5). CO is measured hourly, while particulates are measured daily. There are eight pollution measurement stations in the city of Milan proper (see Figure 2), of which two are inside Area C. The number of monitors varies by pollutant and over time, as not all stations monitor all pollutants.

Table 1 provides descriptive statistics at the monitoring station-day level. The rightmost column includes EU pollution standards for comparison. The European Commission (EC) has the power to levy large fines against non-attainment cities. For example, the EC fined Leipzig $€ 700,000$ per non-attainment day for failing to meet the PM10 standard (Wolff and Perry, 2010).

\section{Estimation}

To explore the effect of policy suspension on traffic volume we estimate a series of equations within the following framework:

\footnotetext{
${ }^{5}$ The reinstated charge now ends at $6 \mathrm{PM}$ on Thursdays, rather than at 7:30PM as before (Corriere della Sera, 2012a). Other features are unchanged.

${ }^{6}$ According to AMAT, the buried sensors are less accurate than the cameras. Neither buried sensor data nor camera data are available prior to 2008 (the cameras had not yet been installed and activated).
} 


$$
\begin{aligned}
\text { traffic }_{t}=\beta * \text { suspension }_{t} & +\lambda * \text { suspension }_{t} * \text { wkend }_{t} \\
& +\bar{\gamma} * \overline{\text { time }_{\mathbf{F E}}}+\overline{\boldsymbol{\theta}} * \overline{\text { date trend }_{\mathbf{t}}}+\overline{\boldsymbol{\eta}} * \overline{\text { weather }}_{\mathbf{t}}+\varepsilon_{t}
\end{aligned}
$$

The traffic variable measures either Area $C$ entries or passing cars, over a day or a 15minute period, with $t$ indexing days. The vector time FE includes fixed effects (FE) for year, month, week, weekend, day of week, and holidays, plus interactions of weekend with year. In addition, it includes dummies for the two-week interim period between Ecopass and Area $\mathrm{C}$ and the interaction of the interim period with weekend. ${ }^{7}$ While the interim period is non-random, we briefly analyze it in Section 5.5.1. The vector $\overline{\text { date trend }}$ is a polynomial trend in date, which controls for long-run trends not captured by our dummies for year, month, etc. ${ }^{8}$ In our primary results below we report estimates using a 7 th-degree trend, following Davis (2008). Weather controls comprise ten-piece linear splines in temperature and positive precipitation. We control for weather because it plausibly influences the choice of public versus private transportation, or car versus motorcycle. The suspension variable is a dummy equal to one for the period July 26, 2012 through September 16, 2012, when the charge was suspended. The error term $\varepsilon$ includes shocks to traffic not captured by our controls, for example, an unusually bad auto accident or the Pope's visit on June 2, 2012. In this and all subsequent equations, the coefficient of interest is $\beta$, the weekday effect of charge suspension. Weekends were unpriced both under the Area C policy and during charge suspension. Intuition suggests the weekend effect $(\beta+\lambda)$ will be negative if there is some scope for weekday-weekend substitution, zero if there is little such scope.

The key identifying assumption underlying both equation 1 and subsequent models is the exogeneity of the suspension variable. That is, we assume that conditional on our rich seasonal and weather controls, the timing of charge suspension is unrelated to other determinants of traffic volume and pollution. This is reasonable because the charge was suspended unexpectedly by a court, as discussed in Section 2 .

For the analysis of spatial substitution, we estimate two panel models at the sensor-day level, with sensor fixed effects. The first specification is as follows ( $s$ indexes sensor):

\footnotetext{
${ }^{7}$ We do not explicitly control for Ecopass because of the year dummies 2008-2011.

${ }^{8}$ The date trend is constructed as follows. We define a variable $t$ equal to one for the first date in our data, two for the second date, and so on. We then control for polynomials in $t$.
} 


$$
\begin{aligned}
& \text { traffic }_{s t}=\overline{\boldsymbol{\beta}} * \text { suspension }_{t} * \overline{\text { distance }_{\mathbf{s}}}+\overline{\boldsymbol{\lambda}} * \text { suspension }_{t} * \text { wkend }_{t} * \overline{\text { distance }_{\mathbf{s}}}
\end{aligned}
$$

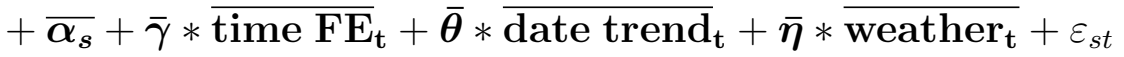

In equation $2 \overline{\text { distance }_{\mathbf{s}}}$ is a vector of dummies for sensors in several distance bins, where distance is measured from the outside of the Area $\mathrm{C}$ boundary. For example, this vector includes a dummy that equals one if a sensor is within one kilometer outside the Area $\mathrm{C}$ boundary, zero otherwise. Interacting these distance dummies with the charge suspension dummy allows us to estimate the effect of charge suspension both inside Area $\mathrm{C}$ and in different donut-shaped regions outside Area C. The second specification is similar, but instead of grouping sensors by distance, we group them into ring roads (unpriced, larger roads encircling the priced area) and other roads (described in more detail in Section 5).

To analyze heterogeneity by public transport availability, we estimate a panel version of equation 1 ( $p$ indexes portal), including portal fixed effects $\overline{\boldsymbol{\alpha}_{\boldsymbol{p}}}$ :

$$
\begin{array}{r}
\text { traffic }_{p t}=\overline{\boldsymbol{\beta}} * \text { suspension }_{t} * \overline{\text { pubtrans }_{\mathbf{p}}}+\overline{\boldsymbol{\lambda}} * \text { suspension }_{t} * \overline{\text { pubtrans }_{\mathbf{p}}} * \text { wkend }_{t} \\
+\overline{\boldsymbol{\alpha}_{\boldsymbol{p}}}+\overline{\boldsymbol{\gamma}} *{\overline{\text { time } \mathbf{F E}_{\mathbf{t}}}}+\overline{\boldsymbol{\theta}} * \overline{\text { date trend }_{\mathbf{t}}}+\overline{\boldsymbol{\eta}} *{\overline{\text { weather }_{\mathbf{t}}}}_{\varepsilon_{p t}}
\end{array}
$$

In the equation above, $\overline{\text { pubtrans }_{\mathbf{p}}}$ is a vector containing a dummy for the presence of public transit, and another for the absence of public transit. We also estimate versions of the model comparing portals with and without bus, tram, and metro service. ${ }^{9}$ By interacting these measures of public transit availability with the suspension dummy, we can identify cross-sectional differences in responses to charge suspension that arise from portal-specific differences in public transit access.

To investigate the effect of suspension on daily average pollution we estimate the following equation:

\footnotetext{
${ }^{9}$ For example, a given portal will have bus equal to 1 if a bus line crosses the boundary of Area $\mathrm{C}$ through that portal. This is a simplification that ignores the effect of being near (but not on) a bus line. If the two effects have the same sign, as is plausible, this specification will bias us against finding a difference between portals with and without a bus line. Similarly, the tram and metro variables equal 1 only if the mode in question passes directly through or beneath the portal in question.
} 


$$
\begin{aligned}
& \ln \left(\text { avg_pollution }_{t}=\beta * \text { suspension }_{t}+\lambda * \text { suspension }_{t} * \text { wkend }_{t}\right. \\
& +\bar{\gamma} * \overline{\text { time }} \mathbf{F E}_{\mathbf{t}}+\overline{\boldsymbol{\theta}} *{\overline{\text { date } \text { trend }_{\mathbf{t}}}}+\eta * \ln \left(\text { avg_pollution }_{t-1}\right)+\overline{\boldsymbol{\delta}} * \overline{\text { atmosphere }_{\mathbf{t}}}+\varepsilon_{t}
\end{aligned}
$$

The dependent variable is the log average level of a pollutant measured over a day, with $t$ indexing days. We conduct the analysis in logs to make the estimates for different pollutants more easily comparable. To avoid the endogeneity problems that arise in a dynamic panel specification, we average over monitors and estimate the model separately for each pollutant and area of Milan. ${ }^{10}$ In order to control for the persistence of pollutants emitted on the previous day, we include one lag of the dependent variable. The lagged pollution variable also controls for the previous day's atmospheric conditions, avoiding the need for functional form assumptions on lagged atmospheric variables. ARPA normalizes the pollu-

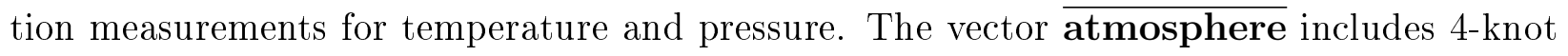
cubic splines in humidity, wind speed, solar radiation, and precipitation, plus a dummy for positive precipitation. As in equation 1, our specification also includes a 7 th-degree trend in date and time fixed effects.

\section{Results}

\subsection{Traffic}

We first provide some semi-parametric evidence on the effect of charge suspension for vehicle types subject to the charge (buses and motorcycles are excluded). Figure 3 plots the residuals from equation 1, omitting the suspension variable. We fit separate degreezero local polynomials for the period June-July 2012 (Area C pricing), August-September (suspension of pricing), and October-November (pricing reinstated). The graph shows a sharp increase in weekday entries into Area $\mathrm{C}$ upon charge suspension, consistent with a surprise announcement. All three fitted lines are flat; there is no evidence of a seasonal trend in the residuals before, during, or after charge suspension. This indicates that our time fixed effects, together with a polynomial trend in date, are effectively controlling for seasonal patterns that might otherwise bias our estimates. There are several large positive residuals between the Sept. 17 reinstatement of pricing and Oct. 1. This may reflect commuters delaying a mode switch before purchasing an October public transit pass.

\footnotetext{
${ }^{10}$ Estimation results from a dynamic panel specification are available upon request. They are extremely similar, as the asymptotic bias is of order $1 / T$ (Nickell, 1981) and our data contain thousands of days.
} 
Table 2 records results from our linear model for all vehicles, charged vehicles (buses and motorcycles excluded), motorcycles (including mopeds and scooters), and other vehicles (primarily police cars and ambulances, which are exempt from the charge). Charge suspension results in approximately 27,000 additional entries per day (14.5 percent) and the estimate is statistically significant at the one percent level. The composition of entries also changes. Entries by charged vehicles increase by roughly 29,000 (19 percent) while entries by motorcycles, which are exempt from the Area $\mathrm{C}$ charge, fall by roughly 2,000 (92 percent). The latter result is not statistically significant. The estimate for other vehicles, predominantly public vehicles like police cars, is small in magnitude and not statistically distinguishable from zero at any conventional significance level. This provides a placebo test, as drivers of public vehicles are exempt and so do not face a price change from charge suspension. The weekend effect of charge suspension is the sum of the estimates in the first and second rows. Estimated weekend effects are positive but not statistically significant under a zero null hypothesis. This implies there is little scope for weekday-weekend substitution. Weekend estimates for our subsequent models are similarly indistinguishable from zero and we omit them for concision. We employ Newey-West standard errors to account for autocorrelation in $\varepsilon_{t}$ out to seven lags. Because of occasional missing data, these standard errors will be biased slightly downward. We have also estimated our models with standard errors clustered at the week level and the results (available upon request) are not meaningfully different. Note that the assumption of independence across clusters fails for days near the boundary of a week, so this is not our preferred method of estimating standard errors.

Table A2 compares our estimated change in vehicle entries to results for 10 other pricing policies. Eight find effects broadly comparable in magnitude, ranging from -3 percent to -22 percent. These include the London ( -18 percent $)$ and Stockholm ( -22 percent) cordon charges studied by Santos (2008) and Eliasson et al. (2009), respectively. Singapore's central Restricted Zone yields two appreciably larger estimates, -44 percent and -52 percent. Small and Verhoef (2007) suggest this policy produced such a dramatic response because the charge was initially set extremely high.

To examine intertemporal substitution, Figure 4 plots the coefficients from a series of 96 regressions, with each 15-minute interval of the day modeled separately. ${ }^{11}$ The estimates show intertemporal substitution in both the morning and the evening. Charge suspension results in approximately 500 fewer entries (23 percent) in the 15 minutes just before the

\footnotetext{
${ }^{11}$ We use Newey-West standard errors to account for serial correlation. For most 15-minute intervals, serial correlation falls to near zero after 7 lags. For the period 11:30PM-5:15AM, however, there are spikes in serial correlation at 14,21 , and 35 days. We hypothesize that this results from the preponderance of public and commercial vehicles during this window.
} 
charge begins at 7:30AM and just after it ends at 7:30PM. This indicates that under the charge, drivers were shifting trips into these unpriced periods. Indeed in the morning the negative estimates are statistically distinguishable from zero (at the 5 percent level) for the entire hour 6:30-7:30AM. Charge suspension increases entries during the 7:30AM-7:30PM period that is priced under the Area $\mathrm{C}$ policy, consistent with the daily average estimates reported in Table 2. The increases achieve local maxima just after 7:30AM and before 7:30PM, suggesting some intertemporal substitution by commuters. The hours 9AM-3PM, however, see roughly uniform increases in traffic under charge suspension. This indicates that non-commuters comprise a large share of marginal drivers.

Such a pattern of responses is the inverse of what is often called "peak spreading." In theory peak spreading affects driver welfare through two channels: 1) by reducing trip duration; and 2) by rescheduling trips (Arnott et al., 1993; Lindsey and Verhoef, 2000). The former welfare effect is positive, but the sign of the latter is theoretically ambiguous. Spreading the peak traffic load increases aggregate schedule delays ${ }^{12}$, but pricing better aligns trip times with drivers' values of schedule delay (Arnott and Kraus, 1998; Lindsey and Verhoef, 2000). Because most air pollution emitted by vehicles is persistent within a day (Seinfeld and Pandis, 2012), peak spreading may not change welfare along this dimension.

Finally we investigate spatial substitution toward roads outside Area C. Table 3 presents results from a panel model at the sensor-day level, estimated from the buried sensor data. Note these data measure passing cars per unit time and the resulting estimates are not directly comparable to those from camera data. Traffic at the average sensor increases by 469 vehicles per day ( 8 percent) and the estimate is statistically significant at the one percent level. This overall result conceals an interesting spatial pattern. Consistent with the models based on camera data, suspension of the charge increases traffic inside Area C. Traffic on the roads within one kilometer outside the Area $\mathrm{C}$ boundary, however, decreases by 1,061 vehicles per day (approximately 18 percent). This estimate is significant at the ten percent level. Both point estimates for roads more than two kilometers outside the boundary are positive, with one statistically significant at five percent and the other not significant. This is consistent with an increase in radial trips (e.g. commutes from a residential neighborhood into the center) from charge suspension. Overall this pattern of results suggests that some drivers respond to the charge by driving around Area C. For drivers seeking to avoid the priced area, the natural route typically involves the Circonvallazione Esterna, a ring of larger roads located $.6 \mathrm{~km}-2 \mathrm{~km}$ outside the Area C boundary. Table 3 shows the estimated effect of

\footnotetext{
${ }^{12}$ In keeping with the theoretical literature, by "delay" we mean a deviation from the desired arrival time, either earlier or later.
} 
charge suspension on these ring roads is large, negative, and significant at the five percent level. Some of this decrease may reflect reduced circumferential commuting to public transit stations. Evaluating this type of spatial substitution has proved difficult in other settings due to confounding factors. In London, for example, the city substantially improved ringroad infrastructure because Transport for London anticipated spatial substitution (Santos, 2004). To the best of our knowledge, ours is the first study to recover an unconfounded driver response on this dimension.

In interpreting these results, it is reasonable to ask whether they capture the shortrun response to a pricing holiday or a long-run response. The initial six-month trial of the Stockholm cordon charge provides some evidence on this point. Eliasson et al. (2009) observe, "... there was some doubt as to whether any traffic reduction would actually take place during a brief and transient trial. Could it be that people would decide to 'sit out' the trial period without changing their travel habits? We now know that the trial indeed had an immediate effect." Effects from Stockholm's initial trial proved very similar to longrun effects (Börjesson et al., 2012). In Milan the suspension of the Area C charge was widely publicized, so the vast majority of residents knew about the change. Evidence on residents' expectations is qualitative and limited. Press accounts suggested Area C pricing might not return (Corriere della Sera, 2012b), but there was likely a range of beliefs about this. The key question is not, however, whether residents expected the suspension to be permanent, but whether they behaved as though it were. We have some suggestive evidence on this point from Figure 3. If residents exhibited habit persistence or slowly updated their beliefs about the suspension, we would expect an upward trend in the residuals during the suspension period. No such trend is apparent; instead the full magnitude of driver responses emerges immediately. This pattern also implies that switching costs across modes, routes, and travel times are not first-order considerations for marginal drivers. Therefore we believe our estimates largely reflect long-run behavior.

There is one respect in which the observed behavior during suspension likely does not correspond to long-run behavior: vehicle portfolios. Intuition suggests they adjust slowly. Given the possibility of renewed pricing, a risk-averse resident of Milan might well have been reluctant to purchase a new vehicle in response to charge suspension. If vehicle portfolios constrained a reasonably large fraction of the population, our estimates represent lower bounds on the magnitude of long-run effects. While our use of a natural experiment does incur this cost on the external validity dimension, it brings offsetting benefits on the internal validity dimension (e.g. avoidance of policy endogeneity concerns).

It is impossible to conduct a full welfare analysis of the Area C policy using our data, but previous work casts light on some of its efficiency properties. Verhoef (2005) studies a cordon 
charge in a general-equilibrium model of a monocentric city with endogenous population density. He finds the optimal cordon location is at 22 percent of the distance from the city center to the city limits. We can compare the location of Milan's cordon to this benchmark. Like many older European cities, Milan is monocentric. From the land area of Area C, we can calculate an idealized radius of $\sqrt{\frac{8.2 \mathrm{~km}^{2}}{\pi}}=1.62$ kilometers. Proceeding in like fashion for the city limits, we obtain an idealized radius of $\sqrt{\frac{181 \mathrm{~km}^{2}}{\pi}}=7.59$ kilometers. Dividing yields a ratio of $\frac{1.62 \mathrm{~km}}{7.59 \mathrm{~km}}=.21$. This suggests that at minimum Milan's cordon is not badly located. We can also evaluate the level of Milan's charge. Mun et al. (2003) simulate a cordon charge using data from Osaka and find the optimal charge is equivalent to roughly 30 minutes' worth of labor income. In Milan this would be about $€ 9$. While Milan differs from Osaka on many dimensions, it is possible that a charge modestly above the current $€ 5$ level would increase welfare. Verhoef (2005) finds that an optimal cordon charge achieves 88-90 percent of the gains from a first-best pricing policy. De Borger and Proost (2001) find an optimal combination of a cordon charge and parking fees can achieve 70 percent of first-best gains. Taken together, this body of research implies that the Area $\mathrm{C}$ pricing policy may be reasonably efficient.

\subsection{Interaction with public transit}

In addition, we investigate the interaction of charge suspension and public transit availability. To that end we estimate a panel model with a portal-day as the unit of observation. The results in Table 4 indicate commuters on routes with public transit available respond much less to the suspension of the charge. Portals on a metro line, for example, show a response that is not statistically distinguishable from zero. ${ }^{13}$

There are at least two plausible explanations for these results. The first relies on cost differences. Assume an identical distribution of preferences for driving on two routes, one with public transit ("Route A") and one without ("Route B"). If a sorting equilibrium holds, commuters on the two routes must achieve equal utility. This implies that if Route A has cheap public transit, it must have expensive car travel. This could be a direct result of public transit, as when road lanes are devoted to tram lines, or a product of transit planning, as when metro lines are placed beneath more congested roads. If a city applies the same charge to cars on both routes, the percentage price change for Route A is much smaller and theory predicts a smaller traffic response.

Alternatively, the results in Table 4 could spring from residential sorting (preference heterogeneity). Suppose people with strong preferences for public transit live near Route A.

\footnotetext{
${ }^{13}$ Portals with public transit may still be generating welfare changes if the composition of traffic is changing, but we cannot evaluate this with our data.
} 
They might not own cars. They might, for example, dislike the claustrophobic conditions that prevail on buses and trains at rush hour. Such individuals might be relatively unresponsive to changes in the price of driving. Assume the initial cost of driving is the same for both routes. Then for a given road price change, there will be more infra-marginal drivers on Route B than Route A.

It is difficult to choose between these explanations using the available data, but Table A1 provides suggestive evidence. When we interact charge suspension with a time-invariant measure of rush-hour congestion, ${ }^{14}$ the response is larger for congested portals without public transit than for uncongested portals without public transit. (Congestion does not matter for portals with public transit.) This result is inconsistent with an explanation based solely on cost differences, which would predict smaller responses on more congested routes. It provides some evidence of preference heterogeneity, but does not exclude the possibility that cost differences drive some of the responses to charge suspension. For further discussion, see Appendix Section A.1.

\subsection{Price response}

Milan's sequence of traffic policies, including both Ecopass and Area C, presents an opportunity to recover another important feature of driver behavior: price responsiveness. Under Ecopass (2008-2011), the weighted average weekday price for passenger vehicles was approximately $€ 0.72$ (author's calculation, based on Rotaris et al. 2010). In January 2012 the Area $\mathrm{C}$ policy increased the weekday price to $€ 5$. This provides potentially exogenous price variation, although the usual concerns about policy endogeneity obtain. We estimate the elasticity of vehicle entries with respect to price using a variant of equation 1, replacing the dependent variable with log entries and the policy variables with log price. This specification does not rely on the natural experiment that forms the basis of our other results. Table 5 reports results. A one percent price increase decreases entries by charged vehicles by .3 percent and the estimate is significant at the one percent level. This estimated response captures the net effect of two changes: the increase in pecuniary cost and the decrease in time cost (from reduced congestion) under the Area $\mathrm{C}$ policy. Given that the Area $\mathrm{C}$ charge is a relatively small part of total trip cost, which includes time, fuel, and depreciation, this demand response is large. For passenger and commercial vehicles elasticities are -.17 and

\footnotetext{
${ }^{14}$ We standardize entries at the portal-15 minute-lane level, then average the resulting values during rush hour periods (over days). Portals with lower values (low rush hour throughput relative to the portal average) are likely more congested. We define a congestion dummy equal to 1 for portals in the bottom 10 percent of the distribution.
} 
-.47, respectively, with both estimates significant at the five percent level. ${ }^{15}$ The estimate for other vehicles is a placebo test of the effect of passenger prices on entries by exempt municipal vehicles; we find no effect. Our elasticity estimates are necessarily local and may not obtain outside the range of prices observed in our data. They suggest, however, that a modest price increase, e.g. from $€ 5$ to $€ 6$, might produce substantial additional reductions in Area $\mathrm{C}$ entries.

If the change in price from Ecopass to Area $\mathrm{C}$ is conditionally exogenous, our estimate captures an internally valid causal effect. The question of external validity remains, however. Theory predicts that demand elasticity will vary with income, preferences, the availability of substitutes, and other factors. To provide a qualitative sense of such factors, Table A2 puts our estimated elasticity in the context of estimates developed in other studies, using data from other locations. At -.3 our overall estimate is modestly larger than most previous findings for cordon charges, which generally range from -.2 to -.1. Estimates for expressway and bridge tolls exhibit more variation, ranging from -.56 to -.06. While some are similar to our result (e.g. Small et al. (2006) for California State Route 91), others are substantially larger or smaller. For example, Odeck and Brathen (2008) find an average price elasticity of -.56 on Norwegian toll roads. Such larger estimates may reflect the often-greater availability of close substitutes for single-facility tolls than for cordon charges.

Some cities manipulate parking prices, rather than road prices, in order to optimize travel demand. Studies of such policies typically estimate parking demand, rather than demand for travel on a given road or demand for cordon crossing. While these estimates are not directly comparable to ours, they may provide an instructive benchmark. In a survey of research findings, the US Transit Cooperative Research Program found a range of parking demand elasticities from -.6 to -.1, with -.3 the mode (Vaca and Kuzmyak, 2005). Using data from exogenous changes in San Francisco parking prices, Pierce and Shoup (2013) estimate an average demand elasticity of -.4.

\subsection{Pollution}

Table 6 reports the pollution effect of charge suspension on weekdays, estimated using equation 4. We focus on CO, PM10, and PM2.5 because these pollutants have direct, negative health effects (Seaton et al., 1995) and all are closely associated with vehicle emissions (Gallego et al., 2013). Estimates show statistically significant increases in CO and PM10, both inside and outside Area $\mathrm{C}$, in the 6 to 17 percent range. These magnitudes are similar to those from our traffic models. The point estimate for PM2.5 outside Area $\mathrm{C}$ is greater

\footnotetext{
${ }^{15}$ We do not separate passenger and commercial vehicles in our analysis of traffic volume because under the Area $\mathrm{C}$ policy they both face the same $€ 5$ price.
} 
at 21 percent, but the standard error is large and the estimate is significant only at the ten percent level. This imprecision may stem from the much shorter period over which PM2.5 data have been collected. For CO we can also estimate the effect for monitors located on the ring roads (Circonvallazione Esterna). This estimate is near zero, which roughly accords with our traffic results in Table 3. As the half-lives of commonly regulated air pollutants are measured in hours or days (Seinfeld and Pandis, 2012), the observed pollution increases likely derive from additional trips and mode shifting, rather than from trip rescheduling.

These pollution effects are large, particularly given that the priced area is small ( 5 percent of land area) and Milan has an unusually clean vehicle fleet. Milan's earlier Ecopass policy, which applied from 2008 through 2011, created incentives for drivers to purchase cleaner vehicles and many did so (Rotaris et al., 2010). This means that for a given number of foregone trips, the effect on pollution would have been smaller in 2012 than in 2007. Like our traffic estimates, our pollution estimates are lower bounds on long-run effects because of the potential for vehicle portfolios to change over the long run.

In order to evaluate the welfare effects of these air pollution changes, we require an estimate of willingness to pay for reductions in PM10 pollution. We adopt estimated annual willingness to pay of $\$ 148.70$ per person per $\mu g / m^{3}$ (in 1982-1984 dollars) from Bayer et al. (2009), who use data from US metropolitan statistical areas. By accounting for migration costs and instrumenting for ambient pollution, this study overcomes several important identification challenges. For comparison, note that the meta-analysis by Smith and Huang (1995) finds a mean marginal willingness to pay of $\$ 110$ (in 1982-1984 dollars) per $\mu \mathrm{g} / \mathrm{m}^{3}$ TSP reduction in US cities. While this estimate is meaningfully smaller than the one from Bayer et al. (2009), this is unsurprising for two reasons: 1) the downward biases in the OLS hedonic specifications analyzed by Smith and Huang (1995); and 2) the higher real income of the US population in the data used by Bayer et al. (2009). The rough similarity between the Bayer et al. (2009) and Smith and Huang (1995) estimates provides some reassurance that our choice is reasonable.

Naturally the use of a willingness to pay estimate from the United States raises benefit transfer concerns. Kaul et al. (2013) find that transfer errors are typically smaller for function transfers than for value transfers. While a full function transfer is beyond the scope of the present exercise, we can scale the Bayer et al. (2009) estimate to account for local income in Milan. As suggested by Ready and Navrud (2006), we employ a PPP-adjusted exchange rate and find that average income in Milan was roughly 85 percent of US income in 2007 (Hammitt and Robinson, 2011; OECD, 2011). Both Smith and Huang (1995) and Hammitt and Robinson (2011) find that the income elasticity of willingness to pay for air pollution reduction is small in wealthier nations, with the latter noting that US agencies often use an 
income elasticity of approximately .5. Multiplying $\$ 149 *(1-(.15 * .5))$ yields approximately $\$ 138$. Converted to 2014 dollars, this becomes $\$ 327$.

With this figure in hand, we can compute the aggregate welfare effects of the PM10 changes in Milan from the Area C policy. Mean PM10 concentration in our data is $48 \mu \mathrm{g} / \mathrm{m}^{3}$ inside Area C, $44 \mu \mathrm{g} / \mathrm{m}^{3}$ outside. The concentration changes implied by our estimates are $1.9^{\mu \mathrm{g} / \mathrm{m}^{3}}$ and $7.5^{\mu \mathrm{g}} / \mathrm{m}^{3}$, respectively. Approximately 77,000 people live in Area $\mathrm{C}$ and 1.2 million outside. The implied welfare gain from the Area $\mathrm{C}$ policy is approximately $\$ 48$ million inside Area $\mathrm{C}$ and $\$ 2.94$ billion outside, for a total of $\$ 3$ billion. This estimate is very large relative to the annual PM10 benefit figures used by transportation researchers in cost-benefit analysis of the Ecopass policy, which have typically been in the range of $60.4-1.3$ million (Rotaris et al., 2010; Danielis et al., 2011). We note that the median transfer error identified by Kaul et al. (2013) is 39 percent, and this does suggest some caution. Even allowing for the possibility of large transfer error, however, our welfare estimate is an order of magnitude larger than those in Rotaris et al. (2010) and Danielis et al. (2011).

The finding that pricing reduces air pollution both inside and outside Area $\mathrm{C}$ speaks to an important distributional question. Opponents of the Area $\mathrm{C}$ policy have argued that it improves air quality in an affluent area while doing nothing to address the remainder of the city (Danielis et al., 2011). The estimates in Table 6 provide evidence against this claim. While spatial substitution may reduce air quality near ring roads, the policy improves air quality in other locations, both inside and outside Area C. Voting behavior is consistent with such a widespread improvement. In a 2011 referendum on road pricing, more than 79 percent voted in favor (Danielis et al., 2011), an outcome that would be unlikely if only Area $\mathrm{C}$ residents benefited from the policy. The successful referendum is somewhat surprising in view of the generally unfavorable public attitudes toward road pricing. As in Stockholm, residents experienced the benefits of road pricing during a trial period before voting and this may have been influential (Eliasson, 2008; Harsman and Quigley, 2010).

\subsection{Robustness checks}

\subsubsection{Traffic}

We estimated all models with the following trends in date: 1) no trend; 2) linear trend; 3) 4th-degree trend; and 4) 7th-degree trend. In nearly all cases the choice of trend had negligible influence on the sign, magnitude and significance of the estimates.

In addition, we compare our primary estimates to those from the interim period between the end of the Ecopass policy and the start of the Area C policy (January 1-15, 2012). During this time drivers could enter the city center without paying, but this period raises identification concerns. First, it was not randomly timed and therefore the potential for 
unobserved confounders (like changes in bus service) is greater than for the period of our natural experiment. Second, because the return of pricing was assured, questions of habit formation and switching costs are more problematic. Third, because this period lasted only two weeks, these models have less statistical power. Nonetheless the interim period provides a rough benchmark against which to evaluate our main results. Table A3 shows that the estimated effects on Area $\mathrm{C}$ entries for all vehicles and charged vehicles are similar in magnitude to our primary results and statistically significant at the one percent level. The estimated effect on motorcycle entries is positive and significant for the interim period, which differs from our primary result and does not accord with theory. The positive sign could reflect the fact that riding a motorcycle in a lower-traffic environment is both safer and more enjoyable.

Table A4 reports spatial substitution results for the interim period. The pattern of results accords with those from our natural experiment, but the decrease in traffic on ring roads is no longer statistically significant. Similarly, Table A5 shows how effects on Area C entries during the interim period vary with public transit availability. (These estimates come from the same model as those in Table 4.) Again the pattern of results is strongly similar to those from our natural experiment, with portals lacking public transit seeing greater increases in traffic.

Taken together, Tables A3, A4, and A5 demonstrate that estimates from the interim period (in January) are quite similar to those from our natural experiment (July-September). This pattern suggests that seasonality in the elasticity of demand for Area $\mathrm{C}$ trips is not a first-order concern. Thus our primary estimates provide evidence on driver responses to pricing that generalizes beyond the time of year at which the natural experiment happened to occur. There remains the possibility of bias from seasonal trends in the level of demand. As discussed in Section 5.1 and illustrated in Figure 3, our time fixed effects and polynomial trend in date appear to effectively control for such trends. Nonetheless we describe seasonal trends in more detail here. Figure A3 shows the seasonal pattern of entries into Area C. The period of the natural experiment includes Italy's traditional vacation season, which sees far fewer Area $\mathrm{C}$ entries in three August weeks. The five remaining weeks of the experiment, however, include some of the busiest weeks of the year (in September). Given the pattern in Figure A3, any failure of our seasonality controls will bias the magnitude of our estimates downward.

Figure 5 displays the "effect" of a placebo charge suspension each year 2008-2011 on Area $\mathrm{C}$ vehicle entries. There is no evidence of an increase in Area $\mathrm{C}$ entries during the placebo periods; if anything they show slight decreases. Similarly, Table A6 reports estimated effects of a placebo suspension for the same dates in 2011, rather than 2012. Estimated magnitudes 
are much smaller than those in our main results and not one is significant.

\subsubsection{Pollution}

Table 7 reports the estimated effects of placebo suspensions for the same dates 2008-2011 (rather than 2012). Half the estimates are negative and most are statistically insignificant, which aligns with the placebo tests from our traffic models and suggests that our main results are not driven by misspecification. The estimated placebos for CO inside Area C (2011) and PM10 outside Area C (2009) are positive and statistically significant, which recommends some caution in interpreting our corresponding primary estimates.

\section{Conclusion}

Our analysis uses a natural experiment to examine behavioral responses and recover causal effects of Milan's Area C road pricing policy. We find the policy reduces traffic and pollution considerably. Drivers respond with intertemporal substitution toward unpriced times and spatial substitution toward unpriced roads outside the charge area. In addition, we show that the effect of pricing on traffic depends on the availability of public transportation. Routes without public transit experience large traffic changes from the Area C charge, while those with public transit experience much smaller changes. We also use long-run changes in Milan's pricing policies to estimate elasticities of traffic with respect to the charge: entries by charged vehicles decrease .3 percent in response to a one percent price increase. This estimate captures the net effect of an increase in the charge and the resulting decrease in time cost from reduced congestion.

Our findings are relevant for policy design. Theory predicts that the substitution behaviors we observe would occur under both optimal and second-best policies, but cities can tailor policy to manage their magnitudes. Cities like Milan, with fixed cordon charges, might reduce intertemporal substitution and move closer to the theoretical optimum by charging a lower but non-zero price for "shoulder" periods adjacent to peak periods. Some drivers might still choose the shoulder period, or switch back to the peak period, but others might switch to public transit or carpool. A city might reduce spatial substitution by expanding the geographic area subject to pricing, such that driving around the priced area would be impractical. Alternatively it might improve roads likely to see policy-driven traffic increases, as London did prior to introducing its cordon charge (Santos, 2004).

Our public transit results also have policy implications. Because responses to pricing vary with transit availability, welfare impacts from pricing will be spatially heterogeneous. Policymakers may wish to consider these distributional impacts when designing a road pricing policy. More generally, our results suggest that road pricing and public transit may be 
substitutes, at least within cities. In areas that already have high levels of public transit, there may be limited scope for reducing traffic via road pricing.

We find suspension of the charge increased weekday concentrations of CO by 6 percent and PM10 by 17 percent. This is a remarkable change in air quality, given: 1) the charge area represents only 5 percent of Milan's land area, and a smaller fraction of the broader metropolitan area; and 2) it is a lower bound on the potential long-run increase. Our estimate is still more surprising in light of the city's relatively clean vehicle fleet. Previous welfare analyses of Milan's Ecopass policy have found net benefits of approximately $€ 7-12$ million per year, even placing extremely low values on air pollution reductions (Danielis et al., 2011). Using an adjusted willingness to pay for PM10 reduction from Bayer et al. (2009), we find that the Area $\mathrm{C}$ policy produces a $\$ 3$ billion welfare gain from air pollution reductions alone.

Pollution effects from similar policies in cities with dirtier fleets could well be larger. More congested cities would also tend to see larger welfare gains. Among the most congested large world cities are Istanbul, Mexico City, and Rio de Janeiro (TomTom, 2014). Among large US cities, New York, Los Angeles, and Chicago see the highest welfare losses from congestion (Lomax et al., 2012). Our results suggest there is scope for road pricing, even in second-best form, to produce very large welfare gains in such environments.

\section{Acknowledgements}

The authors thank Prashant Bharadwaj, Jennifer Burney, Richard Carson, Andrew Chamberlain, Julie Cullen, Gordon Dahl, Jamie Mullins, Kevin Roth, Lanfranco Senn, and two anonymous referees for valuable advice. We also thank AMAT and the Settore Pianificazione e Programmazione Mobilità e Trasporto Pubblico Comune di Milano for data and assistance.

\section{References}

Anderson, M. L., 2014. Subways, strikes, and slowdowns: The impacts of public transit on traffic congestion. The American Economic Review 104 (9), 2763-2796.

Arnott, R., Kraus, M., 1998. When are anonymous congestion charges consistent with marginal cost pricing? Journal of Public Economics 67, 45-64.

Arnott, R., Palma, A. D., Lindsey, R., 1993. A Structural Model of Peak-Period Congestion:

A Traffic Bottleneck with Elastic Demand. The American Economic Review 83 (1), 161179.

Azienda Transporti Milanesi, 2013. Company Profile. Tech. rep. 
Bayer, P., Keohane, N., Timmins, C., Jul. 2009. Migration and hedonic valuation: The case of air quality. Journal of Environmental Economics and Management 58 (1), 1-14.

Börjesson, M., Eliasson, J., Hugosson, M. B., Brundell-Freij, K., Mar. 2012. The Stockholm congestion charges 5 years on. Effects, acceptability and lessons learnt. Transport Policy $20,1-12$.

Carra, I., June 2012. Il sindaco: Salveremo Area C. la Repubblica.

Carra, I., Gallione, A., June 2012. Milano sconfitta dal parcheggiatore sospesa l' area antitraffico. la Repubblica.

City of Milan, 2012. Area C. Accessed December 1, 2012.

URL http: //www. comune.milano.it

Corriere della Sera, Sep. 2012a. Area C, torna il ticket anti traffico da 5 euro Al giovedì telecamere spente alle 18 .

Corriere della Sera, Jul. 2012b. Il Consiglio di Stato sospende Area C Da questa mattina telecamere spente.

Danielis, R., Rotaris, L., Marcucci, E., Massiani, J., 2011. An economic, environmental and transport evaluation of the Ecopass scheme in Milan: three years later.

Davis, L., Feb. 2008. The Effect of Driving Restrictions on Air Quality in Mexico City. Journal of Political Economy 116 (1), 38-81.

De Borger, B., Proost, S., 2001. Reforming transport pricing in the European Union: A modelling approach. Edward Elgar Publishing.

DeCorla-Souza, P., 2004. Recent U.S. Experience: Pilot Projects. Research in Transportation Economics 9 (04), 283-308.

Eliasson, J., Nov. 2008. Lessons from the Stockholm congestion charging trial. Transport Policy 15 (6), 395-404.

Eliasson, J., Hultkrantz, L., Nerhagen, L., Rosqvist, L. S., Mar. 2009. The Stockholm congestion-charging trial 2006: Overview of effects. Transportation Research Part A: Policy and Practice 43 (3), 240-250.

Finkelstein, A., 2009. E-ZTax: Tax Salience and Tax Rates. The Quarterly Journal of Economics 124 (3), 969-1010. 
Foreman, K., 2013. Crossing the Bridge: The Effects of Time-Varying Tolls on Curbing Congestion.

Friedman, M. S., Powell, K. E., Hutwagner, L., Graham, L. M., Teague, W. G., 2001. Impact of changes in transportation and commuting behaviors during the 1996 Summer Olympic Games in Atlanta on air quality and childhood asthma. Journal of the American Medical Association 285 (7), 897-905.

Gallego, F., Montero, J.-P., Salas, C., Nov. 2013. The effect of transport policies on car use: Evidence from Latin American cities. Journal of Public Economics 107, 47-62.

Goh, M., 2002. Congestion management and electronic road pricing in Singapore. Journal of Transport Geography 10, 29-38.

Hammitt, J. K., Robinson, L. A., 2011. The Income Elasticity of the Value per Statistical Life: Transferring Estimates between High and Low Income Populations. Journal of Benefit-Cost Analysis 2 (1), 1-29.

Harsman, B., Quigley, J. M., 2010. Political and Public Acceptibility of Congestion Pricing: Ideology and Self-Interest. Journal of Policy Analysis and Management 29 (4), 854-874.

Invernizzi, G., Ruprecht, A., Mazza, R., De Marco, C., Močnik, G., Sioutas, C., Westerdahl, D., Jul. 2011. Measurement of black carbon concentration as an indicator of air quality benefits of traffic restriction policies within the ecopass zone in Milan, Italy. Atmospheric Environment 45 (21), 3522-3527.

Jones, P., Hervik, A., 1992. Restraining car traffic in European cities: an emerging role for road pricing. Transportation Research Part A: Policy and Practice 26 (2), 133-145.

Kaul, S., Boyle, K. J., Kuminoff, N. V., Parmeter, C. F., Pope, J. C., 2013. What can we learn from benefit transfer errors? Evidence from 20 years of research on convergent validity. Journal of Environmental Economics and Management 66 (1), 90-104.

la Repubblica, Jan. 2008. Milano scatta l'ora dell'Ecopass multe salate per chi sgarra.

Lévy-Lambert, H., 1968. Tarification des Services à Qualité Variable-Application aux Péages de Circulation. Econometrica: Journal of the Econometric Society 36 (3), 564-574.

Lindsey, C. R., Verhoef, E. T., 2000. Traffic Congestion and Congestion Pricing.

Lomax, T., Schrank, D., Eisele, B., 2012. 2012 Urban Mobility Report. Tech. rep., Institute, Texas Transportation. 
Marchand, M., 1968. A Note on Optimal Tolls in an Imperfect Environment. Econometrica $36(3), 575-581$.

Martino, A., 2012. Milano: From Pollution Charge to Congestion Charge. Tech. rep., TRT Trasporti e Territorio.

Meland, S., 1995. Generalised and advanced urban debiting innovations: the GAUDI Project. III: The Trondheim toll ring. Traffic Engineering \& Control 36 (3), 150-155.

Milan Tourism, 2012. Area C. Accessed December 1, 2012.

URL http: //www.turismo.milano.it

Mun, S.-i., Konishi, K.-j., Yoshikawa, K., 2003. Optimal cordon pricing. Journal of Urban Economics 54, 21-38.

Nickell, S., 1981. Biases in Dynamic Models with Fixed Effects. Econometrica 49 (6), 14171426.

Odeck, J., Brathen, S., 2008. Travel demand elasticities and users attitudes: A case study of Norwegian toll projects. Transportation Research Part A: Policy and Practice 42, 77-94.

OECD, 2011. OECD Regions at a Glance. Accessed April 9, 2015.

URL http: //www . oecd-ilibrary.org/sites/reg_glance-2011-en/03/06/index.html

Olszewski, P., Xie, L., 2002. Traffic Demand Elasticity with Respect to Road Pricing - Some Evidence from Singapore. In: Proceedings of the International Conference on Seamless and Sustainable Transport. No. November. pp. 217-228.

Olszewski, P., Xie, L., Aug. 2005. Modelling the effects of road pricing on traffic in Singapore. Transportation Research Part A: Policy and Practice 39 (7-9), 755-772.

Pierce, G., Shoup, D., 2013. Getting The Prices Right. Journal of the American Planning Association 79 (1), 67-81.

Polak, J., Meland, S., 1994. An assessment of the effects of the Trondheim Toll Ring on travel behaviour and the environment. In: Towards an intelligent transport system. Proceedings of the first world congress on applications of transport telematics and intelligent vehiclehighway systems, November 30 - 3 December 1994, Paris, volume 2.

Povoledo, E., Aug. 2012. Effort to Cut Milan Traffic Halted as Court Favors Garage.

Ramjerdi, F., Minken, H., Ostmoe, K., 2004. Norwegian Urban Tolls. Research in Transportation Economics 9 (04), 237-249. 
Ready, R., Navrud, S. 1., 2006. International benefit transfer: Methods and validity tests. Ecological Economics 60 (2), 429-434.

Rotaris, L., Danielis, R., Marcucci, E., Massiani, J., Jun. 2010. The urban road pricing scheme to curb pollution in Milan, Italy. Transportation Research Part A: Policy and Practice 44 (5), 359-375.

Santos, G., 2004. Urban Road Pricing in the U.K. Research in Transportation Economics 9 (04), 251-282.

Santos, G., 2008. London Congestion Charging. Brookings-Wharton Papers on Urban Affairs, 177-234.

Santos, G., Fraser, G., 2006. Road pricing: lessons from London. Economic Policy (April), 263-310.

Seaton, A., Godden, D., MacNee, W., Donaldson, K., 1995. Particulate air pollution and acute health effects. The Lancet 345 (8943), 176-178.

Seinfeld, J. H., Pandis, S. N., 2012. Atmospheric chemistry and physics: from air pollution to climate change. John Wiley \& Sons.

Small, K. A., Gomez-Ibanez, J. A., 1998. Road Pricing for Congestion Management: The Transition from Theory to Policy. In: Road Pricing, Traffic Congestion and the Environment: Issues of Efficiency and Social Feasibility. Vol. 2. pp. 107-123.

Small, K. A., Verhoef, E. T., 2007. The Economics of Urban Transportation.

Small, K. A., Winston, C., Yan, J., 2005. Uncovering the Distribution of Motorists' Preferences for Travel Time and Reliability. Econometrica 73 (4), 1367-1382.

Small, K. A., Winston, C., Yan, J., 2006. Differentiated Road Pricing, Express Lanes, and Carpools: Exploiting Heterogeneous Preferences in Policy Design. Brookings-Wharton Papers on Urban Affairs, 53-96.

Smith, V. K., Huang, J.-c., 1995. Can Markets Value Air Quality? A Meta-Analysis of Hedonic Property Value Models. Journal of Political Economy 103 (1), 209-227.

TomTom, 2014. Tomtom traffic index. Accessed April 11, 2015. URL http://www.tomtom.com/en_gb/trafficindex/\#/list

Toronto Board of Trade, 2011. Toronto as a Global City: Scorecard on Prosperity. Tech. rep. 
Transport for London, 2005. Environment Report 2005. Tech. rep.

Transport for London, 2008. Environment Report 2008. Tech. rep.

Tretvik, T., 2003. Urban road pricing in norway: Public acceptibility and travel behavior. in: Acceptability of transport pricing strategies. In: MC-ICAM Conference, Acceptability of Transport Pricing Strategies.

Vaca, E., Kuzmyak, J. R., 2005. TCRP Report 95. Tech. rep.

Verhoef, E. T., 2005. Second-best congestion pricing schemes in the monocentric city. Journal of Urban Economics 58, 367-388.

Verhoef, E. T., Nijkamp, P., Rietveld, P., 1996. Second-best congestion pricing: the case of an untolled alternative. Journal of Urban Economics 40, 279-302.

Viard, V. B., Fu, S., 2014. The Effect of Beijing's Driving Restrictions on Pollution and Economic Activity.

Vickrey, W., 1963. Pricing in Urban and Suburban Transport. The American Economic Review 53 (2), 452-465.

Wang, L., Xu, J., Qin, P., 2014. Will a Driving Restriction Policy Reduce Car Trips? The Case Study of Beijing, China. Transportation Research Part A: Policy and Practice 67 (September), 279-290.

Wolff, H., 2014. Keep your clunker in the suburb: Low-emission zones and adoption of green vehicles. The Economic Journal 124 (578), F481-F512.

Wolff, H., Perry, L., Aug. 2010. Trends in clean air legislation in europe: Particulate matter and low emission zones. Review of Environmental Economics and Policy 4 (2), 293-308.

Xie, C., 2013. Dynamic Decisions to Enter a Toll Lane on the Road. 


\section{Figures \& tables}

\section{Figures}

Figure 1: Time line of road pricing in Milan

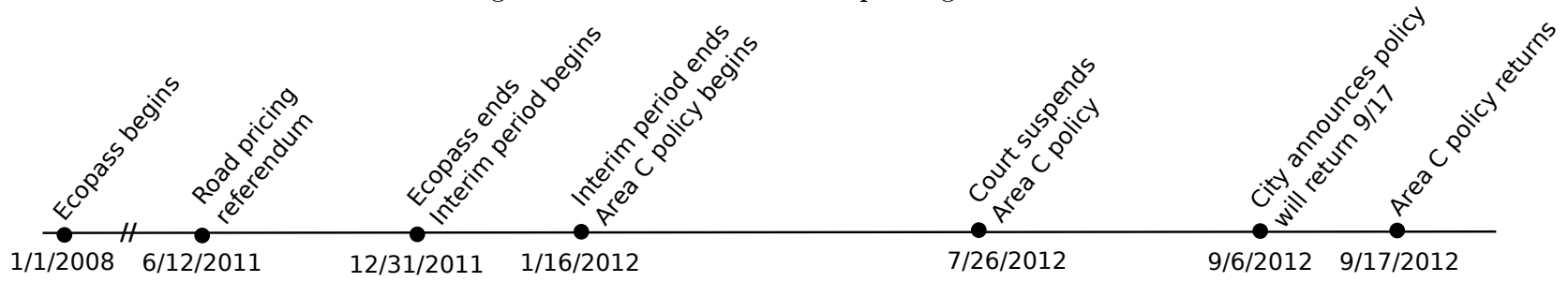

Figure 2: Air pollution monitoring stations in Milan

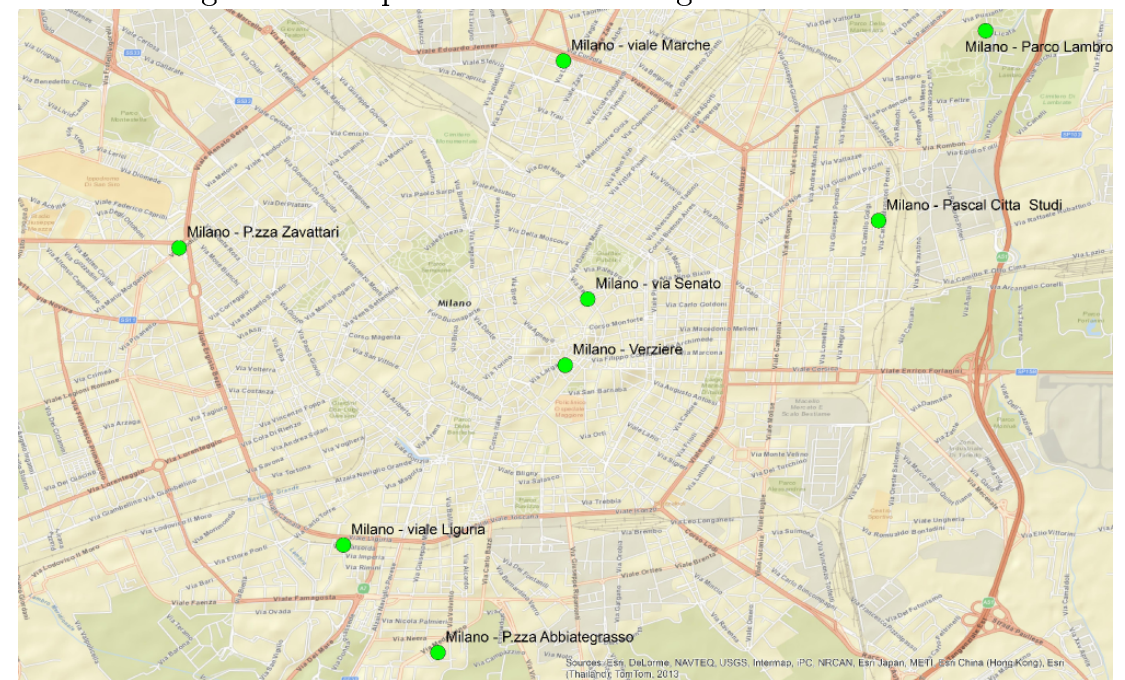

Green circles represent the locations of pollution monitoring stations operated by ARPA Lombardia. Not all stations monitor all pollutants. The via Senato and Verziere stations are inside Area C. The Piazza Zavattari, viale Marche, and viale Liguria stations are on the ring roads (Circonvallazione Esterna). The Piazza Abbiategrasso, Pascal Citta Studi, and Parco Lambro stations are outside the ring roads. 
Figure 3: Effect of Area $\mathrm{C}$ charge suspension on vehicle entries

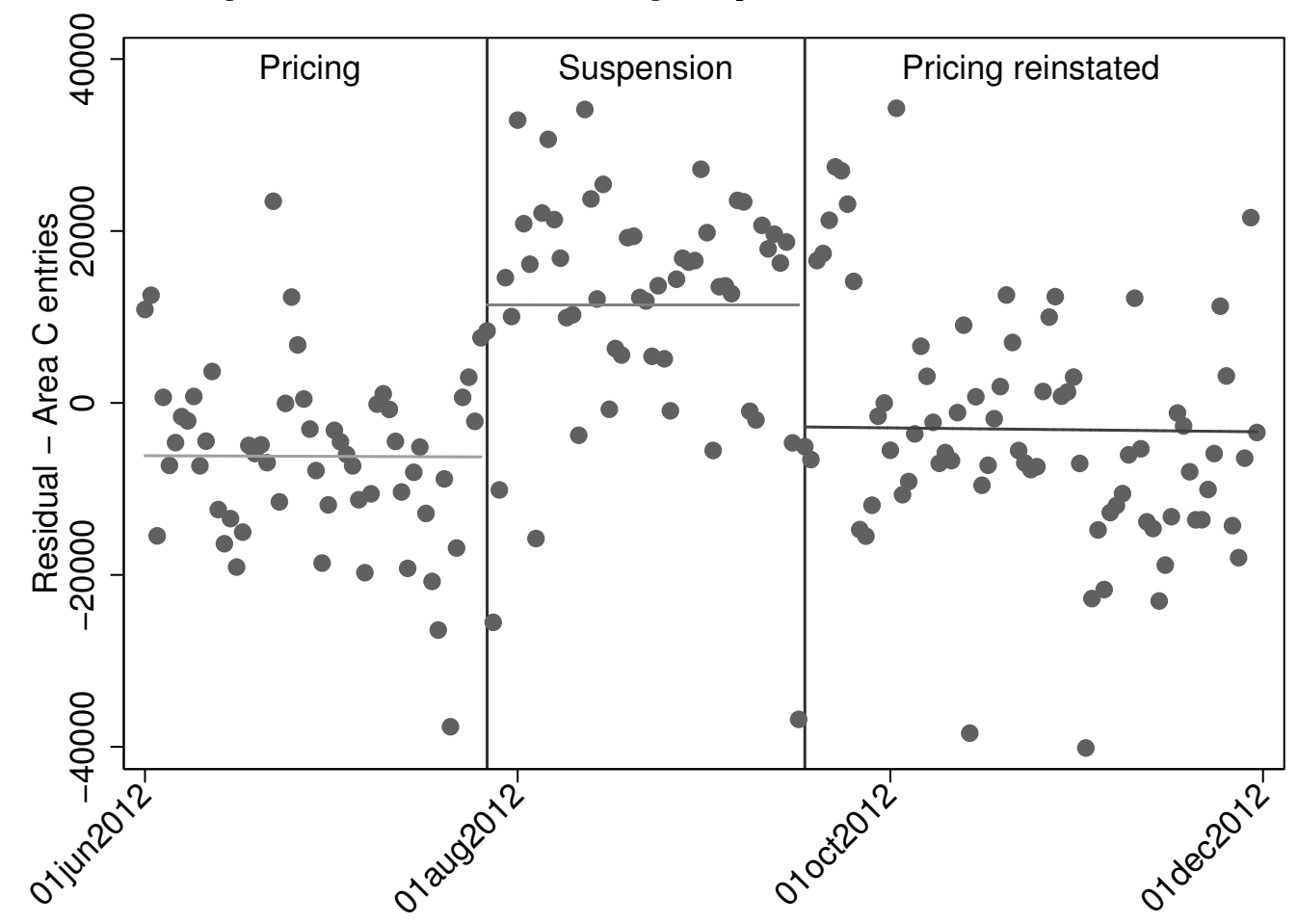

Residuals are from equation (1), with the charge suspension dummy variable excluded. The dependent variable is daily entries into Area $\mathrm{C}$ by vehicles subject to the charge. Each point represents one observation (one day). Fitted lines are based on separate degree-zero local polynomial regressions for pre-suspension, suspension, and post-suspension periods. Time controls include 4 year, 11 month, 51 week, and 5 day of week FEs, a weekend dummy interacted with year, a holiday dummy, a 7th-degree time trend in date, and a dummy for the unpriced January 2012 interim period. Weather controls comprise ten-piece linear splines in temperature and positive precipitation. 
Figure 4: Effect of Area C charge suspension on vehicle entries, by 15-minute interval

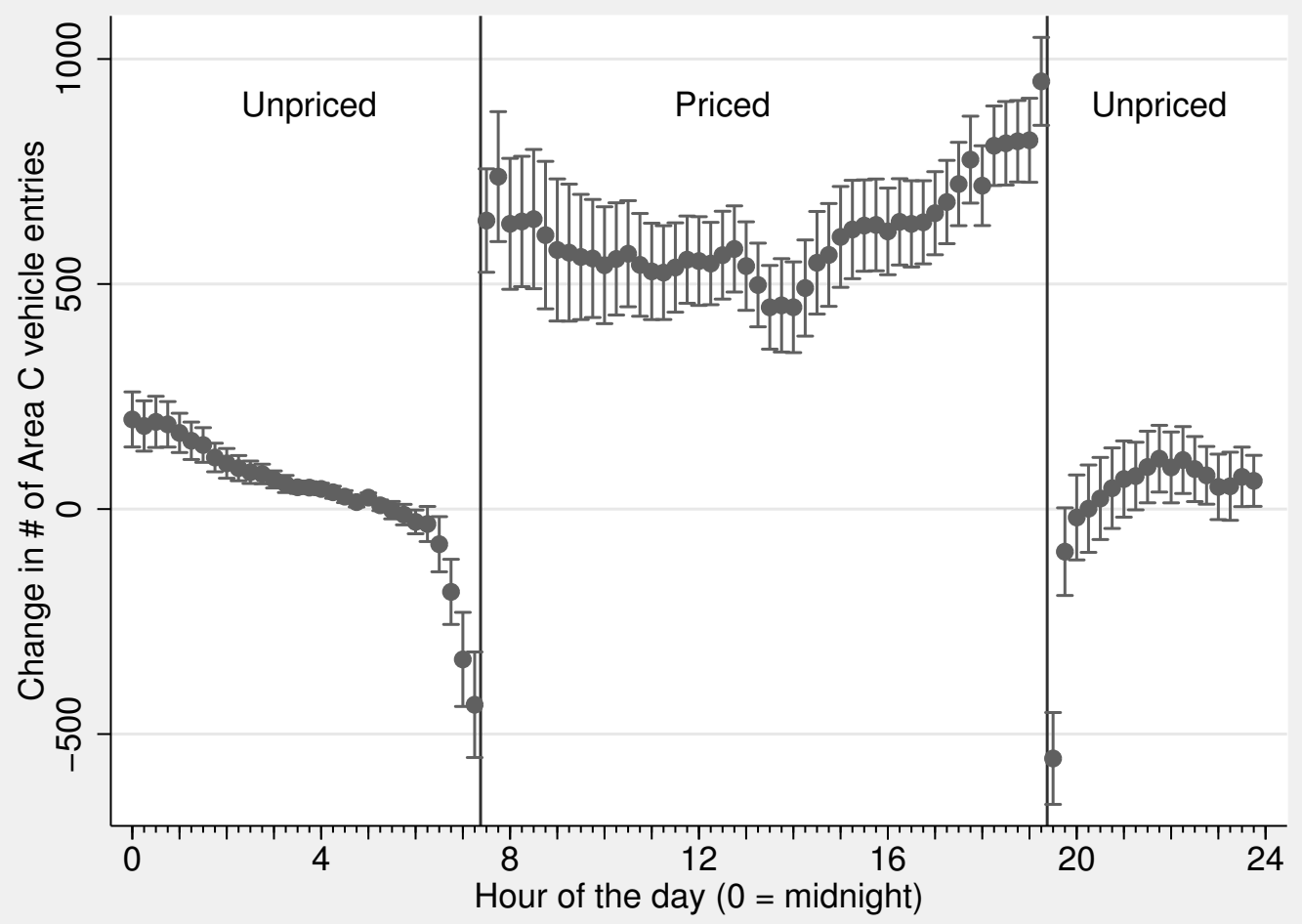

Dependent variable is Area C entries by vehicles subject to charge. Estimates are from equation (1), estimated separately for each 15-minute interval. Whiskers represent Newey-West standard errors multiplied by 1.96 . The lag length is 35 for hours 23.5-5.25, 7 otherwise. "Unpriced" and "priced" labels refer to status of a given interval under the Area C policy, which prices entries 7:30AM-7:30PM. 
Figure 5: Effect of placebo suspensions on Area C vehicle entries
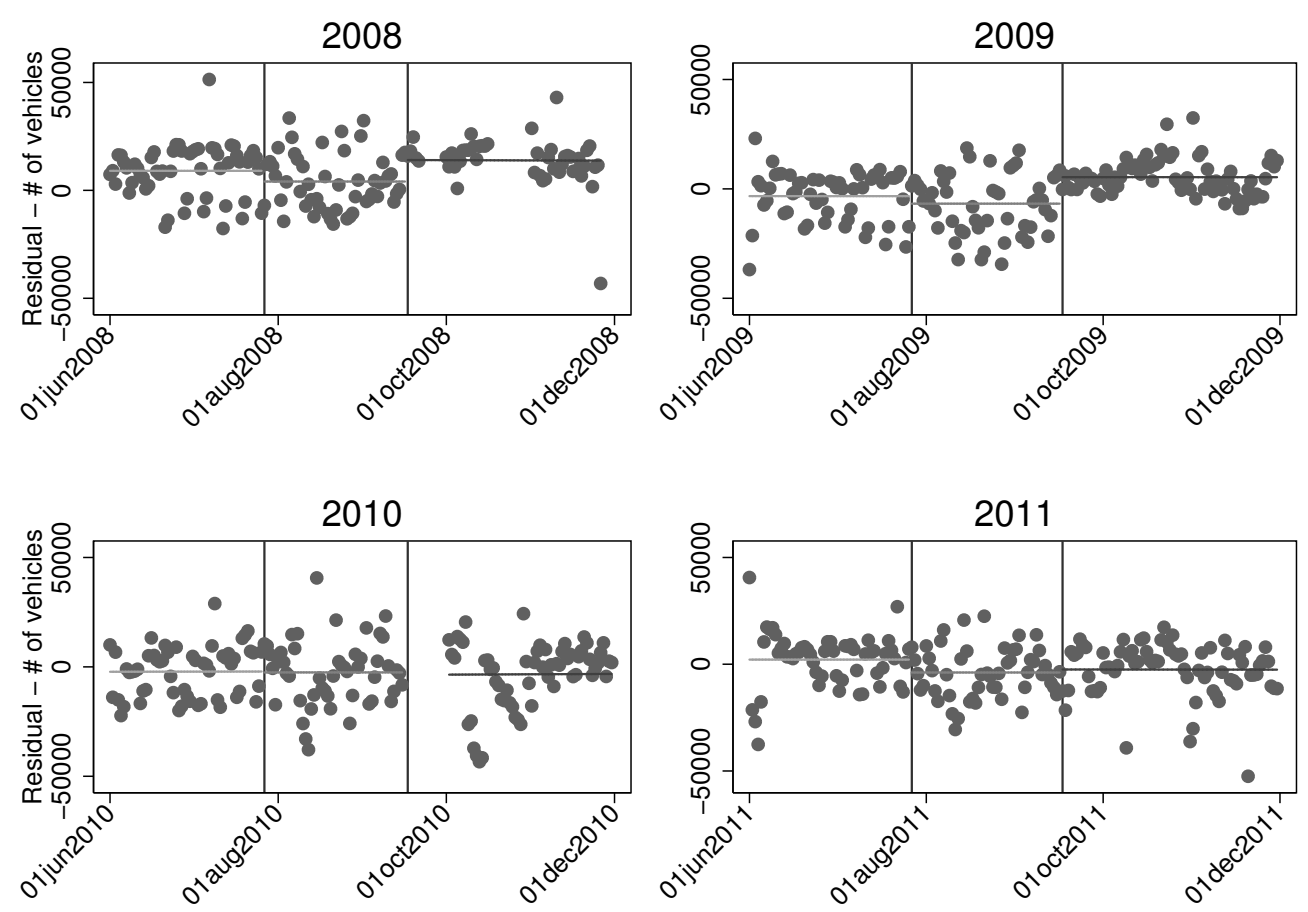

Residuals are from equation (1). Dependent variable is daily entries into Area C by vehicles subject to charge. Each point represents one observation (one day). Fitted lines based on separate degree-zero local polynomial regressions for pre-placebo, placebo, and post-placebo periods (which correspond to the dates of the 2012 natural experiment). Time controls include 0-4 year, 11 month, 51 week, and 5 day of week FEs, a weekend dummy interacted with year, a holiday dummy, a 7th-degree time trend in date, a dummy for the unpriced January 2012 interim period, and a dummy for the June-Sept. 2012 charge suspension. Weather controls comprise ten-piece linear splines in temperature and positive precipitation.

\section{Tables}

Table 1: Descriptive statistics, daily level

\begin{tabular}{|c|c|c|c|c|c|c|c|}
\hline & Units & Mean & Std. dev. & Min & Max & N & EU standard \\
\hline \hline Area C entries & - & 169,744 & 47,628 & 3,905 & 261,172 & 1,737 & - \\
\hline Passing vehicles & - & $2,585,316$ & $1,348,275$ & 37,412 & $5,918,492$ & 1,754 & - \\
\hline CO & $m g / m^{3}$ & 1.26 & .67 & 0 & 7.6 & 17,625 & 10 \\
\hline PM10 & $\mu g / m^{3}$ & 47.66 & 31.07 & 0 & 276 & 9,091 & 40 \\
\hline PM2.5 & $\mu g / m^{3}$ & 33.74 & 26.56 & 0 & 177 & 2,550 & 25 \\
\hline Precipitation & $\mathrm{mm}$ & 2.07 & 6.91 & 0 & 121.2 & 30,929 & - \\
\hline
\end{tabular}

All statistics calculated over daily means. The EU standard for CO is based on a rolling 8-hour mean, while those for PM10 and PM2.5 are based on annual means. 
Table 2: Effect of Area C charge suspension on vehicle entries

\begin{tabular}{lcccc}
\hline \hline & All vehicles & Charged vehicles & Motorcycles & Other vehicles \\
\hline Charge suspension & $26725.2^{* * *}$ & $29266.1^{* * *}$ & -1920.9 & -62.69 \\
& $(5059.5)$ & $(3275.8)$ & $(2447.3)$ & $(54.50)$ \\
Charge suspension* weekend & $-19590.1^{* *}$ & $-23094.3^{* * *}$ & 3295.2 & $171.4^{*}$ \\
& $(9090.5)$ & $(5865.1)$ & $(3566.0)$ & $(98.93)$ \\
Year, month, week, DoW FEs & Yes & Yes & Yes & Yes \\
7th-deg. trend in date & Yes & Yes & Yes & Yes \\
Weather controls & & & & Yes \\
\hline Observations & Yes & Yes & 1720 & 1737 \\
$R^{2}$ & 1737 & 1737 & 0.785 & 0.901 \\
\hline \hline
\end{tabular}

Dependent variable is daily Area C entries. "Other" vehicles are primarily public vehicles like police cars and ambulances, which are exempt from the charge. Each column is a single model corresponding to equation (1). "Charge suspension" corresponds to the weekday effect, while the sum of "Charge suspension" and "Charge suspension*weekend" corresponds to the weekend effect. All specifications include 4 year, 11 month, 51 week, and 5 day of week FEs, a weekend dummy interacted with year, a holiday dummy, a 7th-degree time trend in date, and a dummy for the unpriced January 2012 interim period. Weather controls comprise ten-piece linear splines in temperature and positive precipitation. Newey-West standard errors with 7 lags in parentheses. Significance denoted by: $* \mathrm{p}<0.10,{ }^{* *} \mathrm{p}<0.05,{ }^{* * *} \mathrm{p}<0.01$. The effect on entries by all vehicles is approximately 14.5 percent of the mean. 
Table 3: Weekday effect of Area $\mathrm{C}$ charge suspension on sensor-level traffic volume, by distance outside Area C boundary

\begin{tabular}{lccc}
\hline \hline & Vehicle count & Vehicle count & Vehicle count \\
\hline All roads & $469.8^{* * *}$ & &
\end{tabular}

Area C

0-1 km outside boundary

1-2km outside boundary

$2-4.2 \mathrm{~km}$ outside boundary

$>4.2 \mathrm{~km}$ outside boundary

Non-ring roads

Ring roads

Year, month, week, DoW FEs

7th-deg. trend in date
(131.3)

$1063.2^{* * *}$

$(337.1)$

$-1061.1^{*}$

$(587.0)$

$-161.5$

$(361.0)$

$606.8^{* *}$

(258.3)

515.3

$(391.2)$

\begin{tabular}{lccc} 
Weather controls & Yes & Yes & No \\
\hline Observations & 803086 & 801442 & 801442 \\
$R^{2}$ & 0.085 & 0.093 & 0.093 \\
\hline \hline
\end{tabular}

Dependent variable is daily count of vehicles passing over sensor. Each column is a single model corresponding to equation (2). All specifications include 4 year, 11 month, 51 week, and 5 day of week FEs, a weekend dummy interacted with year, a holiday dummy, a 7th-degree time trend in date, and a dummy for the unpriced January 2012 interim period. Weather controls comprise ten-piece linear splines in temperature and positive precipitation. Distance measured from the outside of the Area $\mathrm{C}$ boundary. Distance dummies set at the $25 \mathrm{th}, 50 \mathrm{th}$, and 75 th percentiles. "Ring roads" denotes the Circonvallazione Esterna, a ring of unpriced, larger roads located $.6 \mathrm{~km}-2 \mathrm{~km}$ outside the Area C boundary. Standard errors clustered at sensor level in parentheses. Significance denoted by: $* \mathrm{p}<0.10, * * \mathrm{p}<0.05,{ }^{* * *} \mathrm{p}<0.01$. The overall effect in the leftmost column is approximately 8 percent of the mean. 
Table 4: Weekday effect of Area $\mathrm{C}$ charge suspension on portal-level vehicle entries, by public transit availability

\begin{tabular}{lr}
\hline \hline & Vehicle co \\
\hline No metro & $883.9^{*}$ \\
& $(160.4$ \\
Metro & 259.9 \\
& $(266.5)$
\end{tabular}

No bus

$905.6^{* * *}$

Bus

No tram

Tram

No public trans.

Public trans.

\begin{tabular}{lcccc} 
Year, month, week, DoW FEs & Yes & Yes & Yes & Yes \\
7th-deg. trend in date & Yes & Yes & Yes & Yes \\
& & & & \\
Weather controls & Yes & Yes & Yes & Yes \\
\hline Observations & 71862 & 71862 & 71862 & 71862 \\
$R^{2}$ & 0.407 & 0.407 & 0.406 & 0.407 \\
\hline \hline
\end{tabular}

Dependent variable is daily Area $\mathrm{C}$ entries through a given portal. Each column is a single model corresponding to equation (3). All specifications include 4 year, 11 month, 51 week, and 5 day of week FEs, a weekend dummy interacted with year, a holiday dummy, a 7th-degree time trend in date, and a dummy for the unpriced January 2012 interim period. Weather controls comprise ten-piece linear splines in temperature and positive precipitation. Standard errors clustered at portal level in parentheses. Significance denoted by: $* \mathrm{p}<0.10, * * \mathrm{p}<0.05, * * * \mathrm{p}<0.01$. 
Table 5: Price elasticity of Area $\mathrm{C}$ vehicle entries

\begin{tabular}{lcccc}
\hline \hline & All charged & Passenger & Commercial & Other \\
\hline $\log ($ Price $)$ & $-0.304^{* * *}$ & $-0.171^{* * *}$ & $-0.467^{* *}$ & -0.0222 \\
& $(0.0944)$ & $(0.0330)$ & $(0.221)$ & $(0.0341)$ \\
Month, week, DoW FEs & Yes & Yes & Yes & Yes \\
7th-deg. trend in date & Yes & Yes & Yes & Yes \\
Weather controls & Yes & Yes & Yes & Yes \\
\hline Observations & 1147 & 1147 & 1147 & 1147 \\
$R^{2}$ & 0.458 & 0.418 & 0.662 & 0.557 \\
\hline \hline
\end{tabular}

Dependent variable is $\log$ daily Area $\mathrm{C}$ entries. Each column is a single model corresponding to equation (1), but with the policy variables replaced by the $\log$ of weekday average price: $€ 0.72$ for passenger vehicles and $€ 3.52$ for commercial vehicles under Ecopass, 65 under Area C. Estimated elasticities reflect traffic response to two changes: 1) a 1 percent increase in the Area $\mathrm{C}$ cordon charge; 2) the resulting cost decrease from reduced congestion and travel time. Weekends were unpriced under both policies and are excluded from the sample. The January 2012 interim period and the July-September 2012 natural experiment period were also unpriced. All specifications include 11 month, 51 week, and 4 day of week FEs, a holiday dummy, and a 7th-degree time trend in date. Co-linearity with price variation prevents the inclusion of year dummies. Weather controls comprise ten-piece linear splines in temperature and positive precipitation. "Other" vehicles are primarily public vehicles like police cars and ambulances, which are exempt from charge. Standard errors clustered at the year-week level. Significance denoted by: $* \mathrm{p}<0.10,{ }^{* *} \mathrm{p}<0.05, * * * \mathrm{p}<0.01$.

Table 6: Weekday pollution effect of Area C charge suspension, by location

\begin{tabular}{lccc}
\hline \hline & $\ln (\mathrm{CO})$ & $\ln (\mathrm{PM} 10)$ & $\ln (\mathrm{PM} 2.5)$ \\
\hline Area C & $0.0606^{* *}$ & 0.0404 & \\
& $(0.0248)$ & $(0.0407)$ & \\
Ring roads & 0.0182 & & \\
& 0.0205 & & \\
Outside & & $0.1696^{* *}$ & $0.2139^{*}$ \\
& & $(0.0676)$ & $(0.1210)$ \\
Lagged pollution & Yes & Yes & Yes \\
Weather controls & Yes & Yes & Yes \\
Year, month, week, DoW FEs & Yes & Yes & Yes \\
7th-deg. trend in date & Yes & Yes & Yes \\
\hline \hline
\end{tabular}

Dependent variable is daily log average pollution in a given area of Milan. Pollution normalized for temperature and pressure by ARPA. Each estimate comes from a different regression corresponding to equation (4). Specifications include 10 year, 11 month, 51 week, and 5 day of week FEs, a weekend dummy interacted with year, a holiday dummy, a 7th-degree trend, a dummy for the unpriced January 2012 interim period, and 1 lag of log average pollution. Weather controls include 4-knot cubic splines in humidity, wind speed, solar radiation, and precipitation, plus a dummy for positive precipitation. Newey-West standard errors with 1 lag in in parentheses. Significance denoted by: $* \mathrm{p}<0.10, * * \mathrm{p}<0.05,{ }^{* * *} \mathrm{p}<0.01$. 
Table 7: Weekday pollution effects of placebo suspensions

\begin{tabular}{|c|c|c|c|}
\hline & $\mathrm{CO}$ & PM10 & PM25 \\
\hline \multicolumn{4}{|l|}{2008} \\
\hline Area $\mathrm{C}$ & $\begin{array}{c}0.0463 \\
(0.0247)\end{array}$ & $\begin{array}{l}-0.0642 \\
(0.0472)\end{array}$ & \\
\hline Ring roads & $\begin{array}{c}-0.0358^{*} \\
(0.0206)\end{array}$ & & \\
\hline Outside & & $\begin{array}{l}-0.0495 \\
(0.0681)\end{array}$ & $\begin{array}{c}0.0474 \\
(0.1399)\end{array}$ \\
\hline \multicolumn{4}{|l|}{2009} \\
\hline Area C & $\begin{array}{l}-0.0095 \\
(0.0198)\end{array}$ & $\begin{array}{c}0.0464 \\
(0.0428)\end{array}$ & \\
\hline Ring roads & $\begin{array}{l}0.0433^{* *} \\
(0.0182)\end{array}$ & & \\
\hline Outside & & $\begin{array}{l}0.1231^{* *} \\
(0.0591)\end{array}$ & $\begin{array}{c}0.1492 \\
(0.0917) \\
\end{array}$ \\
\hline \multicolumn{4}{|l|}{2010} \\
\hline Area C & $\begin{array}{l}-0.0182 \\
(0.0254)\end{array}$ & $\begin{array}{l}-0.0718 \\
(0.0493)\end{array}$ & \\
\hline Ring roads & $\begin{array}{c}0.0063 \\
(0.0184)\end{array}$ & & \\
\hline Outside & & $\begin{array}{c}-0.0258 \\
(0.0736)\end{array}$ & $\begin{array}{c}-0.0498 \\
(0.1054)\end{array}$ \\
\hline \multicolumn{4}{|l|}{2011} \\
\hline Area C & $\begin{array}{c}0.1007^{* * *} \\
(0.0177)\end{array}$ & $\begin{array}{l}-0.0516 \\
(0.0492)\end{array}$ & \\
\hline Ring roads & $\begin{array}{c}-0.0506^{* * *} \\
(0.0190)\end{array}$ & & \\
\hline Outside & & $\begin{array}{c}0.0142 \\
(0.0849) \\
\end{array}$ & $\begin{array}{c}0.0697 \\
(0.1138) \\
\end{array}$ \\
\hline
\end{tabular}

Dependent variable is daily log average pollution pollution in a given area of Milan. Pollution normalized for temperature and pressure by ARPA. Each estimate comes from a different regression corresponding to equation (4). Placebo suspensions run July 27-September 16. Specifications include 10 year, 11 month, 51 week, and 5 day of week FEs, a weekend dummy interacted with year, 7th-degree trend, a holiday dummy, a dummy for the unpriced January 2012 interim period, a dummy for the June-Sept. 2012 charge suspension, and 1 lag of log average pollution. Weather controls include 4-knot cubic splines in humidity, wind speed, solar radiation, and precipitation, plus a dummy for positive precipitation. Newey-West standard errors with 1 lag in parentheses. Significance denoted by: $* \mathrm{p}<0.10,{ }^{* *} \mathrm{p}<0.05,{ }^{* * *} \mathrm{p}<0.01$.

\section{Appendix A}

\section{A.1 Public transit results}

The results in Table A1 provide evidence of some preference heterogeneity (sorting). They are inconsistent with an explanation solely based on cost differences, which would 
predict smaller responses on more congested routes, but do not exclude the possibility that cost differences drive some of the responses to charge suspension.

To see this, consider the framework of Anderson (2014), who derives a condition for choosing rail over driving (simplified here): $c_{\text {rail }}-c_{\text {drive }} \leq P_{0}$, where $c_{\text {rail }}$ and $c_{\text {drive }}$ denote the time costs of driving and the subway. $P_{0}$ is the fiscal cost difference between modes converted to units of time. Suppose three driver types, A, B, and C as illustrated in Figure A1, all of whom initially take the subway. ${ }^{16}$ Drivers $\mathrm{B}$ and $\mathrm{C}$ face higher subway time cost because they must commute circumferentially to the subway line. Assume B and $\mathrm{C}$ are close enough that this cost is the same $\left(c_{\text {rail }, C}=c_{\text {rail }, B}\right)$. Then we have $c_{\text {rail }, C}-c_{\text {drive }, C}<c_{\text {rail }, B}-c_{\text {drive }, B} \leq P_{0}$. Provided $c_{\text {drive }, A}$ is not too small, $c_{\text {rail }, A}-c_{\text {drive }, A}<c_{\text {rail }, C}-c_{\text {drive }, C}<c_{\text {rail }, B}-c_{d r i v e, B} \leq P_{0}$. This framework partially reproduces the public transit results of Table 4; it predicts the marginal drivers will be of types B and C, not A. But it implies more infra-marginal drivers on less congested roads (more type B than $\mathrm{C}$ ), which does not match the pattern of Table A1.

Figure A1: Marginal drivers

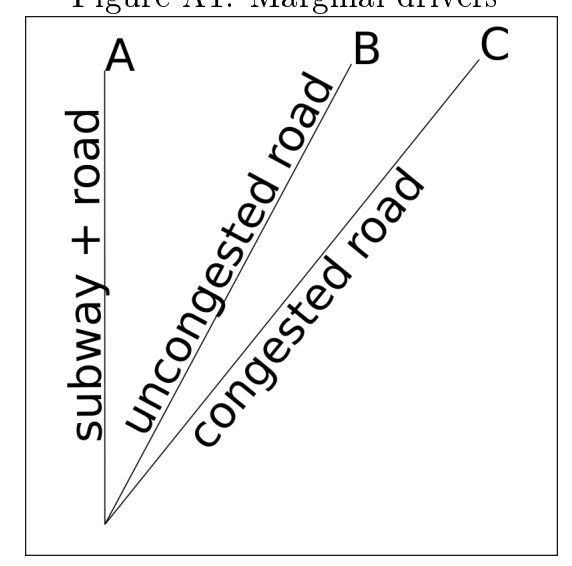

\footnotetext{
${ }^{16}$ While this example is obviously stylized, the radial layout mimics the actual pattern of roads in Milan.
} 
Table A1: Weekday effect of Area $\mathrm{C}$ charge suspension on portal-level vehicle entries, by public transit availability and congestion

\begin{tabular}{lc}
\hline \hline & Vehicle count \\
\hline No public trans. & $1012.6^{* * *}$ \\
& $(211.4)$
\end{tabular}

Public trans.

No public trans. * congested

Public trans. * congested

\begin{tabular}{lc} 
Year, month, week, DoW FEs & Yes \\
7th-deg. trend in date & Yes \\
Weather controls & Yes \\
\hline Observations & 71862 \\
$R^{2}$ & 0.407 \\
\hline
\end{tabular}

Dependent variable is daily Area $\mathrm{C}$ entries through a given portal. Each observation is a portal-day. Each column is a single model corresponding to equation (3). Congested dummy equals 1 for portals where avg standardized peak (8-9:30AM, 5:45$8 \mathrm{PM}$ ) volume is below 10th percentile. All specifications include 4 year, 11 month, 51 week, and 5 day of week FEs, a weekend dummy interacted with year, a holiday dummy, a 7th-degree time trend in date, and a dummy for the unpriced January 2012 interim period. Weather controls comprise ten-piece linear splines in temperature and positive precipitation. Standard errors clustered at portal level in parentheses. Significance denoted by: $* \mathrm{p}<0.10,{ }^{* *} \mathrm{p}<0.05,{ }^{* * *} \mathrm{p}<0.01$.

\section{A.2 Supplemental figures}

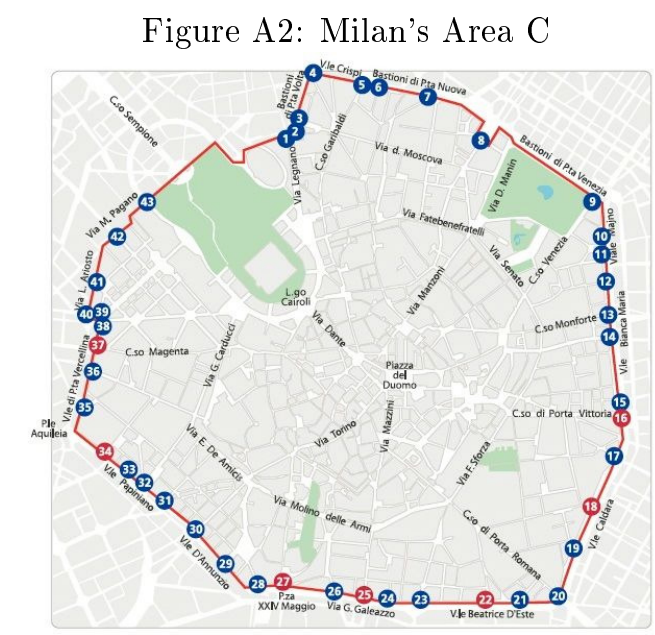

Area $\mathrm{C}$ is the area of the Milan city center that has been priced under the Ecopass and Area $\mathrm{C}$ policies. Numbered circles represent entry portals where the charge is applied using license plate-reading cameras. 
Figure A3: Area C vehicle entries by day of year, 2008-2011

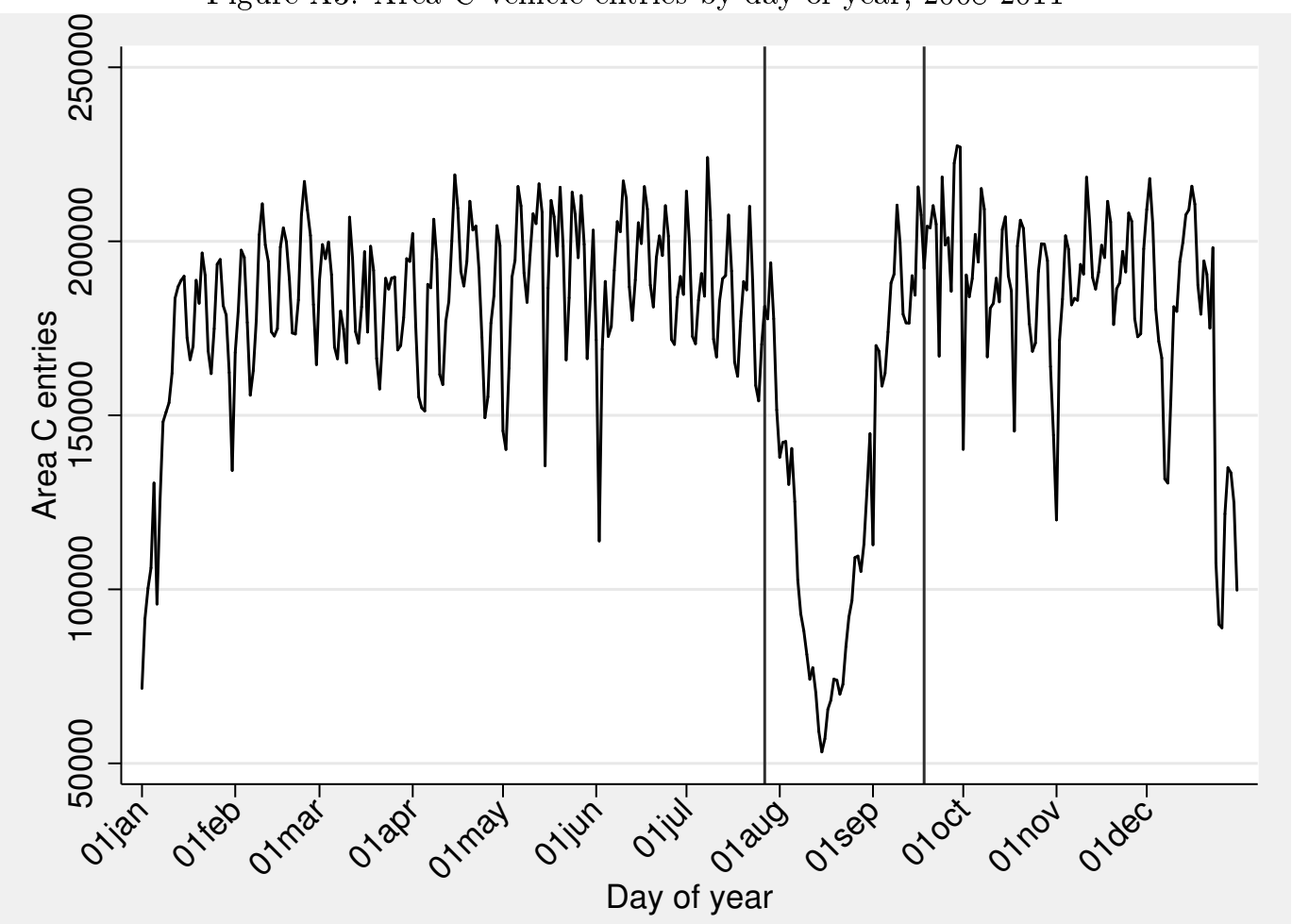

Figure shows average number of Area C entries by day of year 2008-2011, as measured by license plate readers. Vertical lines delimit the period of the 2012 charge suspension. 
Table A2: Comparison of traffic volume effects and elasticities to other empirical road pricing studies

\begin{tabular}{|c|c|c|c|c|}
\hline Paper & Location & Policy & Volume change & Price elasticity \\
\hline Gibson and Carnovale 2015 & Milan & Cordon charge & $+14.5 \%$ & -.30 \\
\hline Jones and Hervik (1992) & Alesund & Toll & - & -.45 \\
\hline Jones and Hervik (1992); Ramjerdi et al. (2004) & Oslo & Cordon charge & $-10 \%$ to $0 \%$ & $-.22,-.03$ \\
\hline Polak and Meland (1994); Meland (1995) & Trondheim & Cordon charge & $-10 \%$ & -.10 \\
\hline Small and Gomez-Ibanez (1998) & Autoroute A1 Paris-Lille & Variable toll & $-4 \%$ & -.16 \\
\hline Small and Gomez-Ibanez (1998) & Singapore Restricted Zone & Cordon charge (1975) & $-44 \%$ & - \\
\hline Goh (2002); Olszewski and Xie (2002) & Singapore Expressways & Toll $(1995)$ & $-16 \%$ & -.22 to -.15 \\
\hline Olszewski and Xie (2002) & Singapore Restricted Zone & Cordon charge $(1976,1989)$ & $-52 \%$ to $-10 \%$ & -.22 to -.32 \\
\hline Tretvik (2003); Ramjerdi et al. (2004) & Bergen & Cordon charge & $>-3 \%$ & - \\
\hline Small et al. (2006) & Orange County SR91 & Variable toll & - & -.36 \\
\hline Odeck and Brathen (2008) & Norway, various & Toll & - & -.56 to -.82 \\
\hline Santos $(2008)$ & London & Cordon charge & $-18 \%$ & - \\
\hline Eliasson et al. (2009) & Stockholm & Cordon charge & $-22 \%$ & - \\
\hline Finkelstein (2009) & Various US & Toll & - & -.06 \\
\hline Foreman (2013) & SF Bay Bridge & Variable toll & $-9 \%,-4 \%$ & -.08 \\
\hline Xie (2013) & Minneapolis I-394 & Variable toll & - & -.14 \\
\hline
\end{tabular}

With the exception of our result, papers are listed in order of publication. Volume changes are from the introduction of pricing or a price change. The volume estimate from our study is positive because we examine the removal of a pricing policy, rather than the imposition of one. Note that our volume change estimate is from a natural experiment, while our price elasticity relies on long-run policy variation. Small and Verhoef (2007) suggest the very large effect of Singapore's initial pricing policy was due to the extremely high charge, which they characterize as far above the second-best optimum level. We separate estimates based on the initial 1977 introduction of pricing in Singapore (Small and Gomez-Ibanez, 1998) from those based on later price changes (Goh, 2002; Olszewski and Xie, 2002). Foreman (2013) provides two estimates: -9\% from a regression discontinuity identification, and $-4 \%$ from a difference-in-differences identification. The rightmost column contains elasticities of traffic volume (cordon crossings or volume on a segment) with respect to price. Unless otherwise noted, they reflect both the direct effect of a toll increase (negative) and the rebound effect from reduced congestion (positive). They generally do not correspond to structural parameters. Elasticities are not available for all of the policies. In some cases authors do not provide sufficient information to calculate them. In others the relevant toll rises from zero to a positive number, leaving the percentage change undefined. In particular, the elasticity estimate of Olszewski and Xie (2002) comes from later price variation, not the initial introduction of the Singapore cordon charge. The Finkelstein (2009) estimate is an average over 33 US facilities. 
Table A3: Comparison of Area C charge suspension to unpriced January 2012 interim period

\begin{tabular}{lcccc}
\hline \hline & All vehicles & Charged vehicles & Motorcycles & Other vehicles \\
\hline Charge suspension & $26725.2^{* * *}$ & $29266.1^{* * *}$ & -1920.9 & -62.69 \\
& $(5059.5)$ & $(3275.8)$ & $(2447.3)$ & $(54.50)$ \\
Interim period & $38692.4^{* * *}$ & $31237.0^{* * *}$ & $7924.1^{* *}$ & 13.11 \\
& $(8308.6)$ & $(6166.6)$ & $(3978.2)$ & $(68.76)$ \\
Year, month, week, DoW FEs & Yes & Yes & Yes & Yes \\
7th-deg. trend in date & Yes & Yes & Yes & Yes \\
Weather controls & & & & Yes \\
\hline Observations & Yes & Yes & 1720 & 1737 \\
$R^{2}$ & 1737 & 1737 & 0.785 & 0.901 \\
\hline \hline
\end{tabular}

Charge suspension estimates are identical to those in main results (Table 2). Dependent variable is daily Area C entries. Each column is a single model corresponding to equation (1). All specifications include 4 year, 11 month, 51 week, and 5 day of week FEs, a weekend dummy interacted with year, a holiday dummy, and a 7th-degree time trend in date. Weather controls comprise ten-piece linear splines in temperature and positive precipitation. Other vehicles are primarily public vehicles like police and ambulances, which are exempt from charge. The interim period January 1-15, 2012, between the Ecopass and Area $\mathrm{C}$ policies, was unpriced. Newey-West standard errors with 7 lags in parentheses. Significance denoted by: $* \mathrm{p}<0.10$, $* * \mathrm{p}<$ $0.05, * * * \mathrm{p}<0.01$. 
Table A4: Weekday effect of unpriced January 2012 interim period on sensor-level traffic volume, by distance outside Area C boundary

\begin{tabular}{lcc}
\hline \hline & Vehicle count & Vehicle count \\
\hline All roads & $1067.6^{* * *}$ & \\
& $(127.4)$ & \\
Area C & & $1597.4^{* * *}$ \\
& $(437.7)$ \\
$0-1 \mathrm{~km}$ outside boundary & 583.8 \\
& $(494.3)$ \\
$1-2 \mathrm{~km}$ outside boundary & $892.9^{* * *}$ \\
& $(344.6)$ \\
$2-4.2 \mathrm{~km}$ outside boundary & $978.0^{* * *}$ \\
& $(308.1)$ \\
$>4.2 \mathrm{~km}$ outside boundary & $1402.0^{* * *}$
\end{tabular}

Non-ring roads

$1330.2^{* * *}$

(150.8)

Ring roads

$-231.0$

$(697.1)$

\begin{tabular}{lccc} 
Year, month, week, DoW FEs & Yes & Yes & Yes \\
7th-deg. trend in date & Yes & Yes & Yes \\
& & & \\
Weather controls & Yes & Yes & No \\
\hline Observations & 803086 & 801442 & 801442 \\
$R^{2}$ & 0.085 & 0.093 & 0.093 \\
\hline
\end{tabular}

Dependent variable is daily count of vehicles passing over sensor. Each column is a single model corresponding to equation (2). All specifications include 4 year, 11 month, 51 week, and 5 day of week FEs, a weekend dummy interacted with year, a holiday dummy, a 7th-degree time trend in date, and a dummy for the July-September 2012 charge suspension. Weather controls comprise ten-piece linear splines in temperature and positive precipitation. Distance measured from the outside of the Area $\mathrm{C}$ boundary. Distance dummies set at the $25 \mathrm{th}, 50 \mathrm{th}$, and 75 th percentiles. "Ring roads" denotes the Circonvallazione Esterna, a ring of unpriced, larger roads located $.6 \mathrm{~km}-2 \mathrm{~km}$ outside the Area C boundary. The interim period January 1-15, 2012, between the Ecopass and Area C policies, was unpriced. Standard errors clustered at sensor level in parentheses. Significance denoted by: $* \mathrm{p}<0.10,{ }^{* *} \mathrm{p}<0.05,{ }^{* * *} \mathrm{p}<0.01$. 
Table A5: Weekday effect of unpriced January 2012 interim period on portal-level vehicle entries, by public transit availability

\begin{tabular}{lr}
\hline \hline & Vehicle cou \\
\hline No metro & $800.9^{* * *}$ \\
& $(118.9)$ \\
Metro & $577.1^{* * *}$ \\
& $(153.9)$
\end{tabular}

No bus

$822.4^{* * *}$

Bus

No tram

Tram

No public trans.

Public trans.

\begin{tabular}{lcccc} 
Year, month, week, DoW FEs & Yes & Yes & Yes & Yes \\
7th-deg. trend in date & Yes & Yes & Yes & Yes \\
Weather controls & Yes & Yes & Yes & Yes \\
\hline Observations & 71862 & 71862 & 71862 & 71862 \\
$R^{2}$ & 0.407 & 0.407 & 0.406 & 0.407 \\
\hline \hline
\end{tabular}

Dependent variable is daily Area $\mathrm{C}$ entries through a given portal. Each column is a single model corresponding to equation (3). All specifications include 4 year, 11 month, 51 week, and 5 day of week FEs, a weekend dummy interacted with year, a holiday dummy, a 7th-degree time trend in date, and a dummy for the July-September 2012 charge suspension. Weather controls comprise ten-piece linear splines in temperature and positive precipitation. The interim period January 1-15, 2012, between the Ecopass and Area C policies, was unpriced. Standard errors clustered at portal level in parentheses. Significance denoted by: $* \mathrm{p}<0.10, * * \mathrm{p}<0.05, * * * \mathrm{p}<0.01$. 
Table A6: Effect of 2011 placebo suspension on Area C vehicle entries

\begin{tabular}{lcccc}
\hline \hline & All vehicles & Charged vehicles & Motorcycles & Other vehicles \\
\hline Placebo suspension (2011) & 2296.6 & 419.8 & 1815.7 & -77.80 \\
& $(5826.7)$ & $(3992.3)$ & $(2297.9)$ & $(48.72)$ \\
Year, month, week, DoW FEs & Yes & Yes & Yes & Yes \\
7th-deg. trend in date & Yes & Yes & Yes & Yes \\
Weather controls & & & & Yes \\
\hline Observations & Yes & Yes & 1720 & Yes \\
$R^{2}$ & 1737 & 1737 & 0.785 & 0.901 \\
\hline \hline
\end{tabular}

Dependent variable is daily Area C entries. "Other" vehicles primarily public vehicles like police cars and ambulances, which are exempt from charge. Each column is a single model corresponding to equation (1). Placebo suspension runs July 27-September 16, 2011. All specifications include 4 year, 11 month, 51 week, and 5 day of week FEs, a weekend dummy interacted with year, a holiday dummy, a 7th-degree time trend in date, a dummy for the unpriced January 2012 interim period, and a dummy for the June-Sept. 2012 charge suspension. Weather controls comprise ten-piece linear splines in temperature and positive precipitation. Newey-West standard errors with 7 lags in parentheses. Significance denoted by: $* \mathrm{p}<0.10,{ }^{* *} \mathrm{p}<0.05,{ }^{* * *} \mathrm{p}$ $<0.01$. 